\title{
Eight new species and additional records of the Pselaphodes complex from Laos and Vietnam, with a key to known species (Coleoptera: Staphylinidae: Pselaphinae)
}

\author{
Zi-Wei YIN ${ }^{1,2)} \&$ Ning LI ${ }^{1)}$ \\ ${ }^{1)}$ Laboratory of Systematic Entomology, College of Life Sciences, Shanghai Normal University, 100 Guilin Road, Xuhui District, \\ Shanghai 200234, China. \\ ${ }^{2)}$ corresponding author; e-mail: pselaphinae@gmail.com
}

\begin{abstract}
Accepted:
$18^{\text {th }}$ January 2021

Abstract. The diversity of the Pselaphodes complex of genera (Pselaphinae: Tyrini) is inPublished online: $18^{\text {th }}$ February 2021 sufficiently documented in Southeast Asia. In this paper eight new species are described and illustrated from Laos and Vietnam: Labomimus cavicornis sp. nov., Labomimus cucphuong sp. nov., Pselaphodes banphabat sp. nov., Pselaphodes dalatensis sp. nov., Pselaphodes jendeki sp. nov., Pselaphodes nongfa sp. nov., Pselaphodes olexai sp. nov., and Pselaphodes parapectinatus sp. nov. New country or provincial records are provided for ten known species: Labomimus bannaus Yin \& Li, 2013, Labomimus maolan Zhang, Li \& Yin, 2019, Labomimus shii (Yin \& Li, 2012), comb. nov. (transferred from Pselaphodes Westwood, 1870), Linan fortunatus Yin \& Li, 2013, Paralasinus gigas Hlaváč \& Nomura, 2001, Pselaphodes hainanensis Yin \& Li, 2013, Pselaphodes incisus Huang, Li \& Yin, 2018, Pselaphodes linae Yin \& Li, 2012, Pselaphodes paraculeus Huang, Li \& Yin, 2018, and Taiwanophodes magnus Bekchiev, 2010. An identification key to the 26 species of the complex that occur in Laos and Vietnam is provided.
\end{abstract}

Key words. Coleoptera, Staphylinidae, Pselaphinae, Tyrini, diversity, new species, new records, identification key, Oriental Region

Zoobank: http://zoobank.org/urn:lsid:zoobank.org:pub:0AEECD1F-1C71-4636-89A7-DA31D2DB73D6

(C) 2021 The Authors. This work is licensed under the Creative Commons Attribution-NonCommercial-NoDerivs 3.0 Licence.

\section{Introduction}

The Pselaphodes complex (sensu HLAvíč 2003) comprises nine morphologically similar genera distributed in the southeastern Palaearctic and Oriental Regions, representing a major radiation of the tribe Tyrini in Asia. A total of 171 species of this complex have been described, with the genus Pselaphodes Westwood, 1870 being the most diverse group (82 spp.), followed by Labomimus Sharp, 1883 (45 spp.), Linan Hlaváč, 2013 (17 spp.), Lasinus Sharp, 1874 (12 spp.), Nomuraius Hlaváč, 2003 (5 spp.), Paralasinus Hlaváč \& Nomura, 2001 (5 spp.), Taiwanophodes Hlaváč, 2003 (2 spp.), Dayao Yin, Li \& Zhao, 2011 (2 spp.), and Indophodes Hlaváč, 2003 (1 sp.) (see Huang et al. 2018a; Huang \& Yin 2019; Li \& Yin 2020; ZHANG et al. 2018, 2019; YIN et al. 2014; YIN 2019, YIN \& ZHANG 2019, and references therein). Most of the recent taxonomic works have been focused on the fauna of China, or to a lesser extent, the Himalayas, whereas only sporadic attention has been given to Indochina. One exception from this unsatisfying situation of knowledge is the genus Paralasinus Hlaváč \& Nomura, 2001, which has been revised to include five species confined to Vietnam, Laos, and Thailand (HLAVÁč \& NomUra 2001). NomURA (2013) provided a checklist of Pselaphinae from Vietnam, and later Nomura (2019) and Nomura \& Pham (2019) listed five species of the complex from Laos, but none of them was formally described or identified at species level.

A considerable number of new materials of the Pselaphodes complex from southeast Asia have become available from several European public and private collections since 2015. Here, we pay attention to the fauna of Vietnam and Laos. Other than Paralasinus, at present only two species of each Nomuraius and Pselaphodes, and one species of each Taiwanophodes and Lasinus are known 
from this area (HUANG \& YIN 2018; HUANG et al. 2018b; BeKCHIEv 2010; BeKCHIEv et al. 2013, 2019), while no species of Labomimus and Linan has been reported. The present paper provides descriptions of eight new species, and new distributional records for 10 previously described ones, which increases the species number in Vietnam and Laos from 11 to 26. An identification key to males of the Pselaphodes complex that occur in these two countries is given.

\section{Material and methods}

The material treated in this study is housed in the following public and private collections:

MHNG Muséum d'histoire naturelle de Genève, Switzerland (Giulio Cuccodoro);

NMPC National Museum, Prague, Czech Republic (Martin Fikáček);

NSMT National Museum of Nature and Science, Tsukuba, Japan (Shûhei Nomura);

SNUC Insect Collection of Shanghai Normal University, Shanghai, China (Zi-Wei Yin);

VBGG Volker Brachat's private collection (Geretsried, Germany).

The text of the specimen labels is quoted verbatim. Dissected body parts including genitalia are preserved in Euparal on a plastic slide that was placed on the same pin as the specimen. The habitus image was taken using a Canon 5D Mark III camera in conjunction with a Canon MP-E $65 \mathrm{~mm}$ f/2.8 1-5X Macro Lens, and a Canon MT-24EX Macro Twin Lite Flash was used as the light source. Images of the morphological details were produced using a Canon G9 camera mounted on an Olympus CX31 microscope under transmitted or reflected light. Zerene Stacker ver. 1.04 was used for image stacking. All images were optimized and grouped into plates in Adobe Photoshop CS5 Extended.

The following acronyms are used in the text:

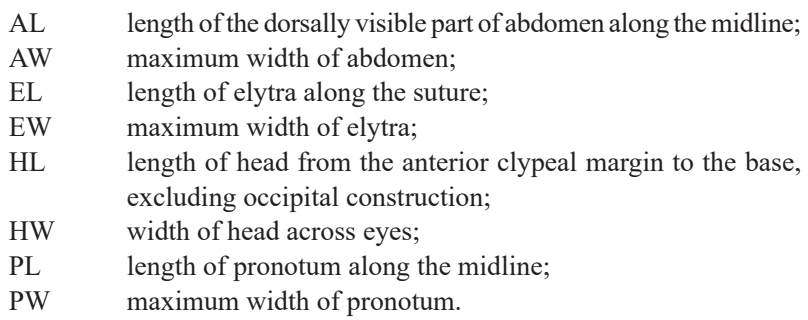

The body length is a sum of HL, PL, EL and AL. The abdominal tergites and sternites are numbered following CHANDLER (2001) in Arabic (starting from the first visible segment) and Roman (reflecting their true morphological position) numerals, starting from tergite 1 (IV), or sternite 1 (III).
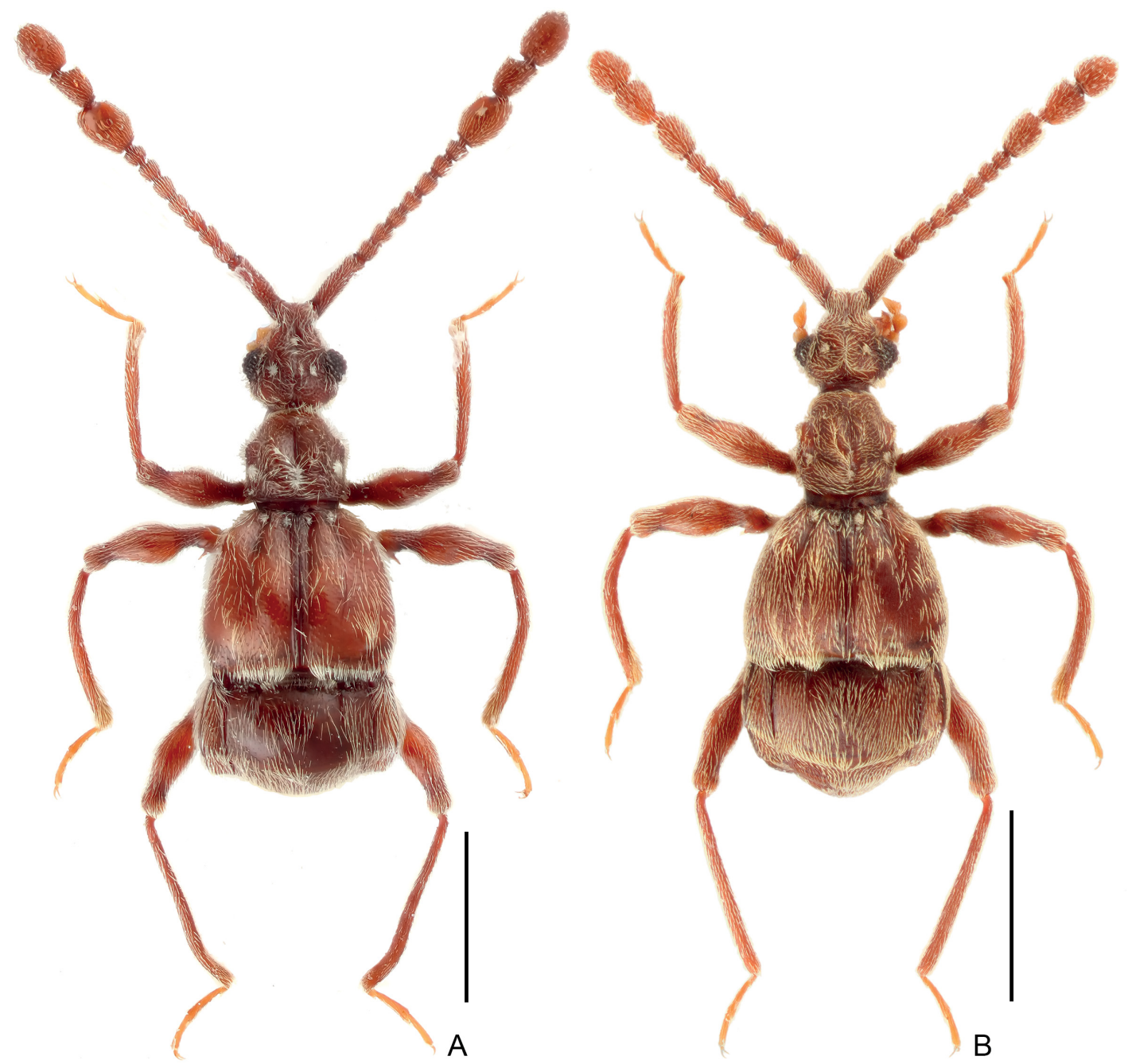

Fig. 1. Dorsal habitus of Labomimus males. A - L. cavicornis sp. nov.; B - L. cucphuong sp. nov. Scale bars: $1 \mathrm{~mm}$. 


\section{Taxonomy}

\section{Labomimus bannaus Yin \& Li, 2013}

Labomimus bannaus Yin \& Li, 2013 in Yin et al. (2013a: 344)

Type locality. China: Yunnan, Xishuangbanna, Menglun Town, Mandajiu Villege, $21.93429^{\circ} \mathrm{N}, 101.27697^{\circ} \mathrm{E}$, alt. $640 \mathrm{~m}$.

Additional material examined ( 57 specimens). LAOS: KHAMMOUAN: $36 \AA$, 'LAOS centr., Khammouan pr., BAN KHOUN NGEUN viii. env., 17.v.-6.vi.2007, 300 m, M. Štrba lgt' (MHNG, SNUC); 1 §, 'same locality, 4-16.xi., 25-30.xi.2000, $18^{\circ} 07^{\prime} \mathrm{N}, 104^{\circ} 29^{\prime} \mathrm{E}, 250 \mathrm{~m}$ Jendek \& Šauša' (MHNG); 1 ô, 'same locality, $17^{\circ} 43^{\prime} \mathrm{N}, 105^{\circ} 09^{\prime} \mathrm{E}, 22 . \mathrm{V} .-8 . V I .2001$, alt.

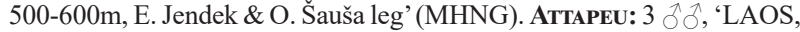
ATTAPEU prov. Annam Highlands Mts, Dong Amphan NBCA, ca. 1160 m. NONG FA [crater lake], env. $15^{\circ} 05.9^{\prime} \mathrm{N}, 107^{\circ} 25.6^{\prime} \mathrm{E}$, Jiří Hájek leg. 30.iv.- 6.v.2010' (NMPC); 1 đે, 'LAOS, Attapu prov., Bolaven Plateau, 18-30.IV.99, 15 km SE of Ban Houaykong, 900 m, Štrba lgt' (MHNG). ChaMPasaK: $2 \hat{\jmath} \hat{\jmath}$, 'LAOS, Champasak prov., Bolaven Plateau, 10-18. IV.99, route Pakse-Paksong, Banitou env., 800 m, Strba lgt' (MHNG); 1 ỏ, 'S Laos, Champasak prov. Bolaven Plateau, 10-18.4.99, Route No.23, Pakse-Paksong, Banitou env, 900 m, Jendek \& Šauša' (MHNG). BolikHaMsaI: 1 dै, 'LAOS, 1-18.v.2001, Bolikhamsai prov., $18^{\circ} 21^{\prime} \mathrm{N}$, $105^{\circ} 08^{\prime} \mathrm{E}$, Ban Nape (8 km NE), 600 m, V. Kubán̆ leg' (MHNG); 1 ․, 'LAOS: 27.iv-1.v.97, 70 km NE Vientiane BAN PHABAT, $150 \mathrm{~m}$, N1 $18^{\circ} 16^{\prime}$, E $103^{\circ} 11^{\prime}$, Sausa \& Jendek' (MHNG). VIETNAM: ĐônG NAI: 6 Jै. 'S-VIETNAM, Nam Cat Tien Nat. Park, 1.-15. 5. 1994, Pacholatko \& Dembicky' (MHNG, SNUC). NinH BìnH: $3 \hat{\delta} \delta$, 'VIETNAM N, 100 km s from Hanoi CUC-PHUONG nat. Park, 02.-12.5.1991, leg. E. Jendek' (VBGG); $1 \hat{\jmath}$, 'VIETNAM N, 02.-12.5.91, 100 km S from Hanoi CUC-PHUONG nat. park, E. Jendek leg' (VBGG).

Comments. The male of Labomimus bannaus can be readily recognized by a large disc-like process at the apex of antennomere 9 , basally expanded antennomere 10 , curved antennomere 11, as well as by the unique form of aedeagus. This species was originally described from Xishuangbanna, Yunnan, southern China, and is here newly recorded from Vietnam and Laos. There is no obvious morphological difference between the population from China and those from Laos and Vietnam.

Distribution. China: Yunnan; Vietnam: Ninh Bình, Đồng Nai; Laos: Bolikhamsai, Khammouan, Champasak, Attapeu (YIN et al. 2013a; this paper). First country records for Laos and Vietnam.

\section{Labomimus cavicornis sp. nov.}

$$
\text { (Figs 1A, 2) }
$$

Type material (6 specimens). HolotyPe: VIETNAM: Đòng NaI: $\delta$, 'S-VIETNAM, Nam Cat Tien Nat. Park, 1.-15.5.1994, Pacholatko \& Dembicky' (MHNG). ParaTYPes: VIETNAM: Đòng NaI: 5 ổ, same label data as for holotype (MHNG, SNUC).

Diagnosis. Male body length 3.09-3.23 mm. Antennomere 9 with broad depression in apical half, with disc-like impression inside depression; antennomeres 10 broadly depressed and antennomere 11 deeply concave on ventral side. Horn-like metaventral processes in lateral view elongate and bifurcate at apices. Protibia with short, blunt preapical projection; mesotrochanter with acute ventral spine. Median lobe of aedeagus asymmetric, narrowing apically; parameres broad at bases and narrowed in apical halves; endophallus with spine-like structures and one elongate sclerite. Female unknown.

Description. Male (Fig. 1A). Body length 3.09-3.23 mm. Head slightly broader than long, HL $0.56-0.61 \mathrm{~mm}$, HW
0.59-0.63 mm; eyes prominent, each composed of about 41 facets. Antennomeres 2-8 of similar shape, each moniliform; antennomeres 9-11 (Fig. 2A) forming distinct club; antennomere 9 with large depression in apical half, and one disc-like impression inside depression; antennomeres 10 broadly depressed and antennomeres 11 with broad and deep concavity on ventral side. Pronotum (Fig. 2B) approximately as long as wide, PL $0.56 \mathrm{~mm}$, PW 0.56-0.59 $\mathrm{mm}$, narrowed anteriorly at apical $2 / 5$. Elytra broader than long, EL 0.87-0.94 mm, EW 1.11-1.15 mm. Horn-like metaventral processes (Fig. 2C) in lateral view elongate and curved upward, bifurcate at apices. Protrochanter (Fig. 2D) with tiny ventral tooth; profemur angularly expanded at middle; protibia (Fig. 2E) with blunt process before apex; mesotrochanter (Fig. 2F) with acute ventral spine; mesofemur (Fig. 2F), metatrochanter and metafemur (Fig. 2G) simple. Abdomen broad at base and narrowed apically, AL 1.00-1.02 mm, AW 1.11-1.20 mm. Sternite 7 (IX) (Fig. 2H) hemi-membranous, elongately oval. Aedeagus (Figs 2I-K) $0.55 \mathrm{~mm}$ long; median lobe asymmetric dorso-ventrally, narrowing apically; parameres short, curved ventrally, broad at bases and abruptly narrowed for apical halves; endophallus comprising one large, elongate and curved sclerite, and numerous hemi-membranous spinelike structures at apical part.

Female. Unknown.

Comparative notes. This is a very distinctive species which can be easily separated from all congeners by unique modification of the male antennal club.

Etymology. The new species is a Latin adjective composed of cavus (-a, -um; meaning hollow, concave, excavated) and cornis (-is, $-e$; meaning horned), referring to the strongly depressed and concave antennal clubs of the male.

Distribution. Vietnam: Đồng Nai.

\section{Labomimus cucphuong sp. nov.} (Figs 1B, 3)

Type material (1 specimen). Holotype: VIETNAM: Ninh Bình: 'VIETNAM N, 100 KM s from Hanoi CUC-PHUONG nat. Park, 02.12.5.1991, leg. E. Jendek' (MHNG).

Diagnosis. Male body length $2.84 \mathrm{~mm}$. Antennomere 9 with round, deep ventral concavity in apical half; antennomere 10 strongly constricted at base and forming nodule-like stem, broadly impressed for most area of ventral side. Horn-like metaventral processes in lateral view slightly broaden at apices. Protrochanter with blunt ventral projection, protibia with small tubercle at apex; mesotrochanter with small triangular protuberance. Median lobe of aedeagus almost symmetric dorsoventrally; parameres thin and elongate; endophallus with seven sclerites and one structure. Female unknown.

Description. Male (Fig. 1B). Body length $2.84 \mathrm{~mm}$. Head winder than long, HL $0.48 \mathrm{~mm}$, HW $0.56 \mathrm{~mm}$; eyes prominent, each composed of about 43 facets. Antennomeres 3-8 gradually becoming shorter, antennomeres 9-11 (Fig. $3 \mathrm{~A}$ ) forming distinct club; antennomere 9 with round, deep ventral concavity in apical half, antennomere 10 strongly constricted near base and forming nodule-like stem, most part of ventral surface broadly impressed, antennomere 11 
much shorter than 10, truncate at base and with round apex. Pronotum (Fig. 3B) slightly longer than wide, PL $0.56 \mathrm{~mm}$, PW $0.50 \mathrm{~mm}$, narrowed anteriorly at apical $2 / 5$. Elytra broader than long, EL $0.74 \mathrm{~mm}$, EW $1.05 \mathrm{~mm}$. Horn-like metaventral processes (Fig. 3C) in lateral view slightly expand at apices. Protrochanter (Fig. 3D) with blunt projection; profemur angularly expanded at middle; protibia (Fig. 3E) with small tubercle at apex; mesotrochanter (Fig. 3F) with short triangle protuberance; mesofemur (Fig. 3F), metatrochanter and metafemur (Fig. 3G) simple. Abdomen broad at base and narrowed apically, AL $0.96 \mathrm{~mm}$, AW 1.07 mm. Aedeagus (Figs 3H-J) $0.51 \mathrm{~mm}$ long; median lobe almost symmetric dorsoventrally, in lateral view curved and narrowed at apex; each paramere with two preapical setae; endophallus composed of seven sclerites and one membranous structure.

Female. Unknown.

Comparative notes. This species can be readily recognized and distinguished from all other members of the genus by uniquely modified male antennal club.

Etymology. The new species is named after the type locality, Cúc Phương National Park. The species name is a noun in apposition.

Distribution. Vietnam: Ninh Bình.
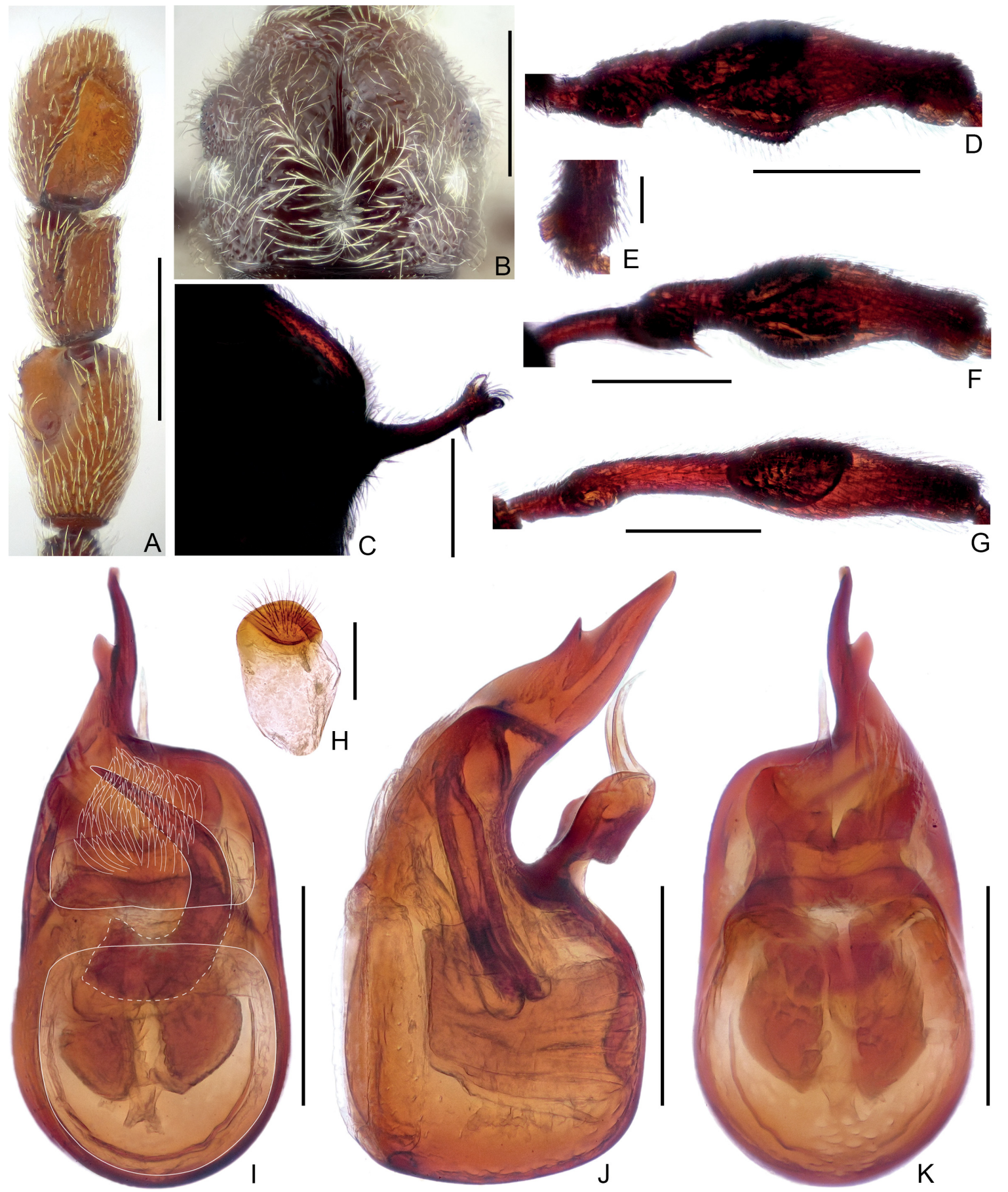

Fig. 2. Male diagnostic features of Labomimus cavicornis sp. nov. A - left antennal club, in lateroventral view; B - pronotum; C - metaventral process, in lateral view; $\mathrm{D}$ - protrochanter and profemur; $\mathrm{E}$ - apex of protibia; $\mathrm{F}$ - mesotrochanter and mesofemur; $\mathrm{G}$ - metatrochanter and metafemur; $\mathrm{H}-$ sternite 7 (IX); I-K - aedeagus, in dorsal (I), lateral (J), and ventral (K) view. Scale bars: $0.3 \mathrm{~mm}$ in A, B, D, F, G; $0.2 \mathrm{~mm}$ in C, I, J, K; $0.1 \mathrm{~mm}$ in H; 0.05 mm in E. 


\section{Labomimus maolan Zhang, Li \& Yin, 2019}

Labomimus maolan Zhang, Li \& Yin, 2019: 513

Type locality. China: Guizhou, Libo County, Maolan N. R., Dongdai, $25^{\circ} 17^{\prime} 13^{\prime \prime} \mathrm{N}, 107^{\circ} 56^{\prime} 23^{\prime \prime} \mathrm{E}, 792 \mathrm{~m}$.

Additional material examined (1 specimen). VIETNAM: LÀo CAI: 1 1., 'VIETNAMN, $22^{\circ} 20^{\prime} \mathrm{N}, 103^{\circ} 50^{\prime} \mathrm{E}$, SAPA (Lao Cai), 25.5-10.6.1991, leg. E. Jendek' (VBGG).

Comments. Labomimus maolan was originally described from Guizhou, southwestern China, and is here newly record from Lào Cai, northern Vietnam. The population from Vietnam slightly differs from that from China in the shape of the apical portion of the aedeagal median lobe, and in endophallus; otherwise, the form of the antennal clubs and the leg spination are identical.

Distribution. China: Guizhou; Vietnam: Lào Cai (ZHANG et al. 2019; this paper). First country record for Vietnam.

Labomimus shii (Yin \& Li, 2012), comb. nov.

Pselaphodes shii Yin \& Li, 2012 in YIN et al. (2012: 79)

Type locality. China: Hainan Prov., Ledong County, Jianfengling N. R., Yulingu, $18.74686^{\circ} \mathrm{N}, 108.92988^{\circ} \mathrm{E}$, ca. $635 \mathrm{~m}$.

Additional material examined ( 2 specimens). VIETNAM: HòA BìnH: $2 \hat{\jmath}$, 'Vietnam, Hoa bing, 4.-7.6.1986, Ha son binh prov., Jan Horák lgt.' (MHNG)

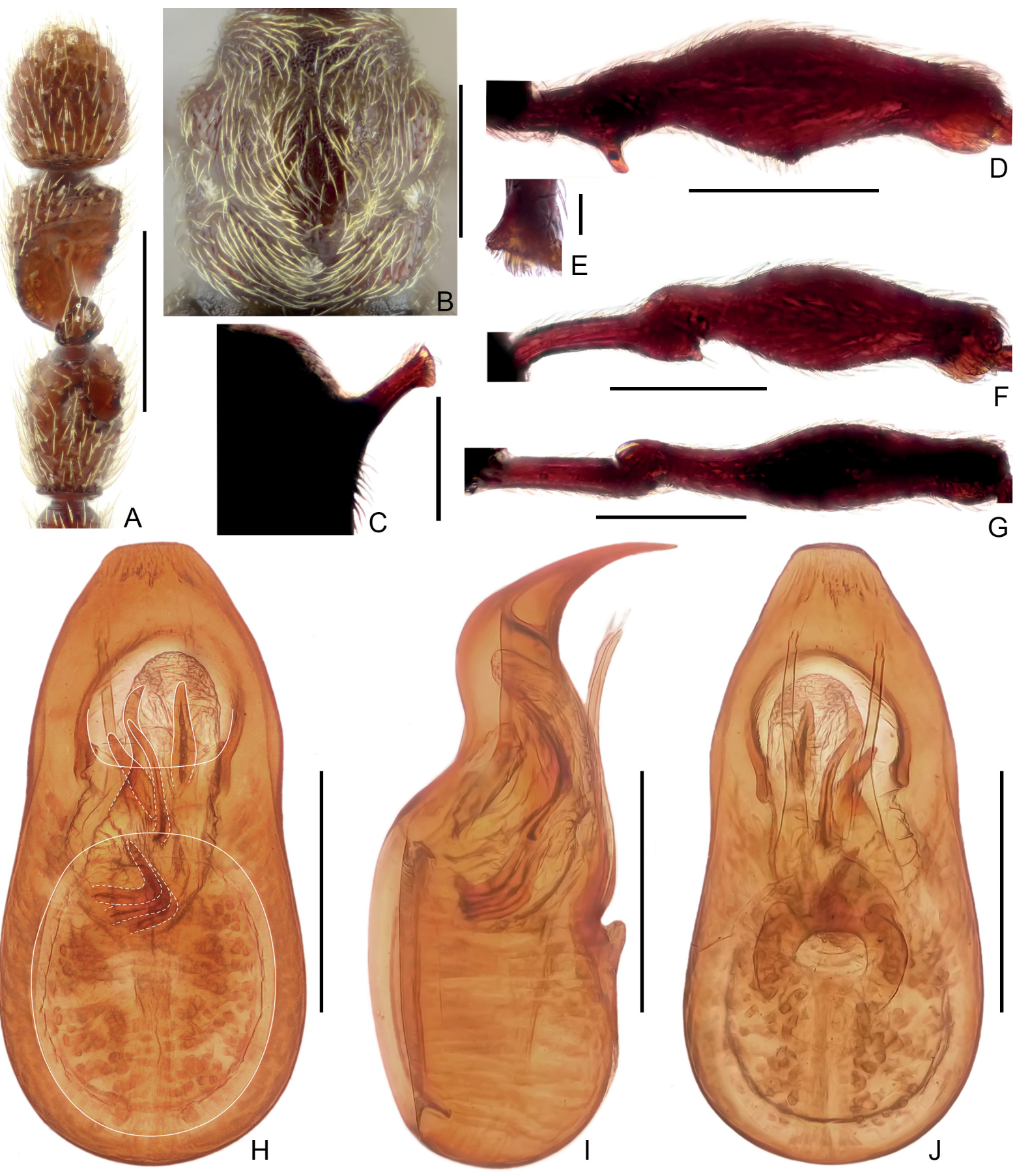

Fig. 3. Male diagnostic features of Labomimus cucphuong sp. nov. A - right antennal club, in ventral view; B - pronotum; C-metaventral process, lateral view; D - protrochanter and profemur; E - apex of protibia; F - mesotrochanter and mesofemur; $\mathrm{G}$ - metatrochanter and metafemur; H-J - aedeagus, in dorsal (H), lateral (I), and ventral (J) view. Scale bars: $0.3 \mathrm{~mm}$ in A, B, D, F, G; $0.2 \mathrm{~mm}$ in C, H, I, J; $0.05 \mathrm{~mm}$ in E. 
Comments. This species was originally described based on three males from Hainan, as a member of the genus Pselaphodes. It is characterized primarily by the male antennomere 9 with an acute anteromedial triangular process, the long horn-like metaventral processes, and a broad median lobe of aedeagus in lateral view. Due to the presence of a distinct metaventral fovea between the metaventral processes, this species is here transferred from Pselaphodes to Labomimus. No distinct intraspecific variation has been detected between the populations of China and Vietnam. Distribution. China: Hainan; Vietnam: Hòa Bình (YIN et al. 2012; this paper). First country record for Vietnam.

\section{Linan fortunatus Yin \& Li, 2013}

Linan fortunatus Yin \& Li, 2013a: 147.

Type locality. China, Guangxi Province, Jinxiu County, Lianhuashan Mountain, $1100 \mathrm{~m}, 24^{\circ} 09^{\prime} 21^{\prime \prime} \mathrm{N}, 110^{\circ} 06^{\prime} 48^{\prime \prime} \mathrm{E}$.

Additional material examined (35 specimens). VIETNAMN: VĩNH

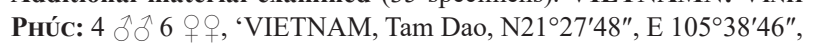

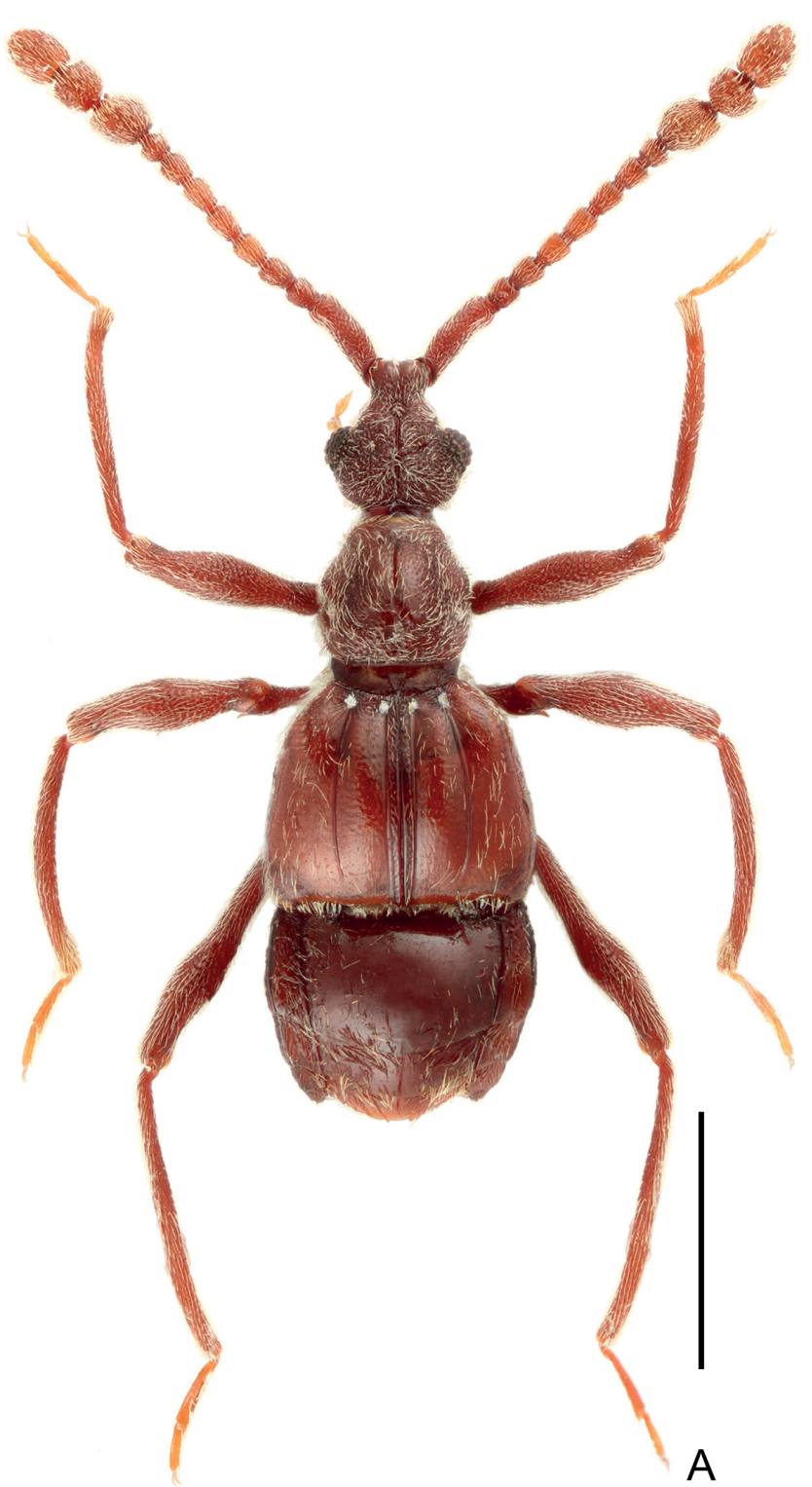

16.V.2012, $1229 \mathrm{~m}$, sift 06, V. Grebennikov lgt'(MHNG, SNUC); 5 त 5 ○, "VIETNAM, Tam Dao, N21 292'27", E105³7'49”, 13.V.2012, 1128 m, sift 03, V. Grebennikov lgt' (MHNG, SNUC); 1 \ 49 , 'VIETNAM, Tam Dao, N21 ${ }^{\circ} 27^{\prime} 44^{\prime \prime}$, E105'38'55", 17.V.2012, 1185 m, sift 07, V. Gre-

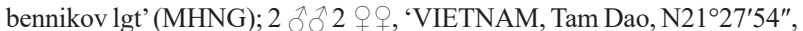
E105³8'44", 12.V.2012, 1218 m, sift 02, V. Grebennikov' (MHNG); 3 ô่ 1 우, “VIETNAM, Tam Dao, N 2127'54", E 105³8'56", 14.V.2012, 1237 m, sift 04, V. Grebennikov lgt' (MHNG); 1 §,, 'Mt. Tam Dao (950), Vinh Phu Prov [N-VIETNAM], 13.v.2003. S Nomura leg' (MHNG); 1 , 'same locality and collector, except '21. v. 2003' (MHNG).

Comments. The male of L. fortunatus can be readily separated from all congeners by denser setae at the posterolateral margins of pronotum and the anterolateral margins of elytra, as well as by apically broadened antennomere 9 , which is massively impressed on the lateral surface. The female, which was previously unknown, lacks these dense setae on pronotum and elytra. This species was originally described from Guangxi, southern China, and is here reported from northern Vietnam. The populations from China and Vietnam differ only slightly in the shape of the

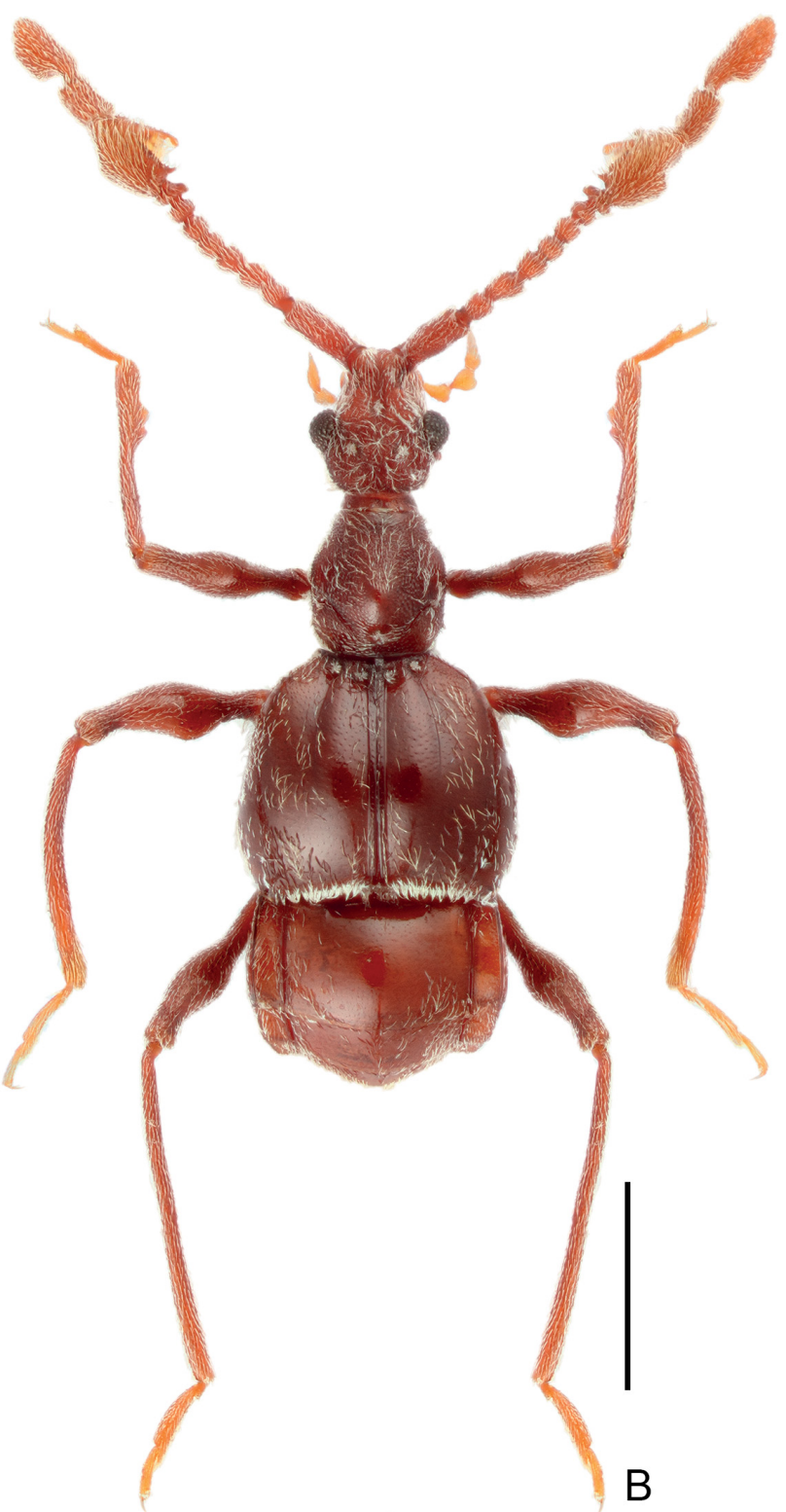

Fig. 4. Dorsal habitus of Pselaphodes males. A - P. banphabat sp. nov.; B - P. dalatensis sp. nov. Scale bars: $1 \mathrm{~mm}$. 
apex of the median lobe and the position of the endophallic sclerites of aedeagus.

Distribution. China: Guangxi; Vietnam: Vĩnh Phúc (YIN \& LI 2013a; this paper). First country record for Vietnam.

\section{Paralasinus gigas Hlaváč \& Nomura, 2001}

Paralasinus gigas Hlaváč \& Nomura, 2001: 166

Type locality. S. Laos, Attapeu Prov, Bolaven Plateau, Nong Lom lake env., $15 \mathrm{SE}$ of Ban Houaykong, $800 \mathrm{~m}$.

Type material examined (18 specimens). PARATYPES: LAOS: ATTAPEU: 2 ô ô, 'S Laos, Attapu prov., Bolaven Plateau, 18-30.4.99, $15 \mathrm{~km}$ SE of Ban Houaykong, Nong Lom lake env., 800 m, Jendek \& Šauša / PARATYPUS (red, printed), Paralasinus gigas sp. nov. P. Hlaváč det., 2000' (MHNG). THAILAND: Chanthaburi: 16 , 'Khao Krok (L.T., 300 m), Kaeng Hang Naw, Chantha Buri, THAILAND, 25-27.iv.1997,
Sadahiro Ohmomo leg. / PARATYPUS (red, printed), Paralasinus gigas sp. nov. P. Hlaváč det., 2000’ (NSMT).

Additional material examined (3 specimens). LAOS: KHAMMOUAN: $3 \delta^{\jmath}$, 'LAOS centr., Khammouan prov., NAKAI env., $17^{\circ} 43^{\prime} \mathrm{N}, 105^{\circ} 09^{\prime} \mathrm{E}$, 22.V.-8.VI.2001, alt. 500-600 m, E. Jendek \& O. Šauša lgt.' (MHNG, SNUC).

Comments. Paralasinus gigas was originally described based on materials from Attapeu, Laos, and Chanthaburi, Thailand. It is characterized by large body size (3.7-4.0 $\mathrm{mm})$, markedly elongate antennomere 1 in relation to antennomere 2, unique pattern of golden smooth area of antennomeres 4-10 (according to the original description, the golden smooth area is present only on antennomeres $7-10$, which is most likely based on incorrect observation), and by distinctive form of aedeagus. The additional
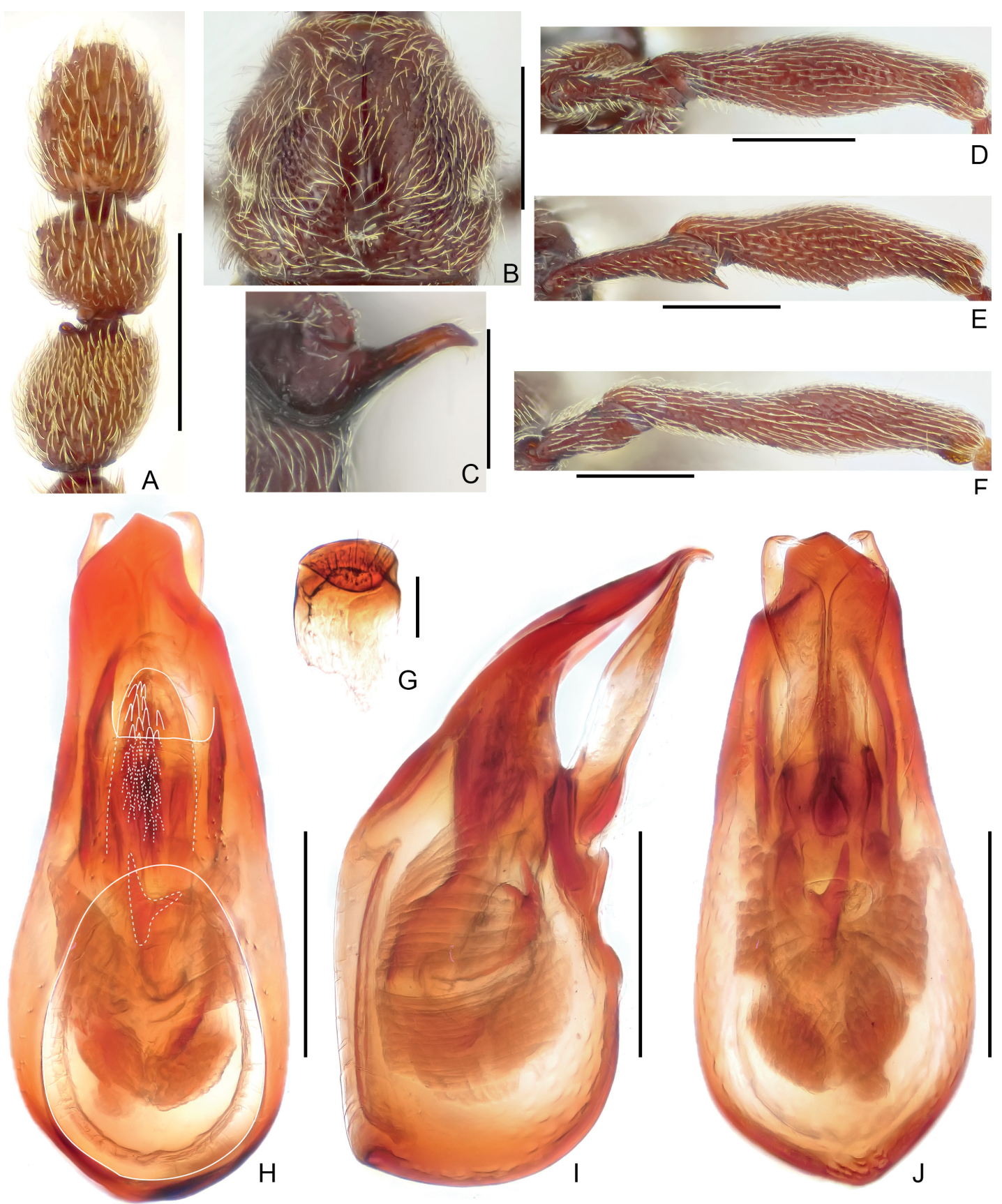

Fig. 5. Male diagnostic features of Pselaphodes banphabat sp. nov. A - left antennal club, in ventral view; B - pronotum; C - metaventral process, lateral view; D - protrochanter and profemur; E - mesotrochanter and mesofemur; F - metatrochanter and metafemur; $\mathrm{G}$ - sternite 7 (IX); $\mathrm{H}-\mathrm{J}$ - aedeagus, in dorsal $(\mathrm{H})$, lateral (I), and ventral (J) view. Scale bars: $0.3 \mathrm{~mm}$ in A, B, D, E, F; $0.2 \mathrm{~mm}$ in C, H, I, J; $0.1 \mathrm{~mm}$ in G. 
material examined here extends the distributional range of this species to Khammouan, central Laos.

Distribution. Laos: Attapeu, Khammouan; Thailand: Chanthaburi (Hlavéč \& Nomura 2001; this paper). First provincial record for Khammouan.

\section{Pselaphodes banphabat sp. nov. (Figs 4A, 5)}

Type material (1 specimen). HоLотуре: LAOS: BolikhamsaI: $\hat{\jmath}$, 'LAOS: 27.iv-1.v.97, 70 km NE Vientiane BAN PHABAT, 150 m, N18 $16^{\prime}$, E10311', Sausa \& Jendek' (MHNG).

Diagnosis. Male body length $3.05 \mathrm{~mm}$. Antennomeres 9-11 enlarged and forming club, antennomeres 9 and 10 each with small tubercle at apex and base, respectively. Horn-like metaventral processes long, in lateral view narrowing apically. Protrochanter with tiny ventral spine, mesotrochanter with acute ventral spine; mesofemur with small tooth at middle. Median lobe of aedeagus slightly asymmetrical dorso-ventrally; parameres elongate; endophallus composed of spine-like structures and a single sclerite. Female unknown.

Description. Male (Fig. 4A). Body length $3.05 \mathrm{~mm}$, Head approximately as long as wide, HL $0.59 \mathrm{~mm}$, HW $0.57 \mathrm{~mm}$; eyes prominent, each composed of about 44 facets. Antennomeres 9-11 (Fig. 5A) enlarged and forming distinct club, antennomere 9 with a round tubercle at apex, antennomere 10 with similar but larger tubercle at base. Pronotum (Fig. 5B) as long as wide, PL and PW $0.59 \mathrm{~mm}$, roundly narrowing apically at apical $2 / 5$. Elytra much broader than long, EL $0.83 \mathrm{~mm}$, EW $1.05 \mathrm{~mm}$. Horn-like metaventral processes (Fig. 5C) long, in lateral view narrowing apically. Protrochanter (Fig. 5D) with tiny spine at ventral margin, profemur simple; mesotrochanter (Fig. 5E) with acute ventral spine, mesofemur with small tooth at middle; metatrochanter and metafemur (Fig. 5F) simple. Abdomen broad at base and narrowed posteriorly, AL $0.98 \mathrm{~mm}$, AW $1.05 \mathrm{~mm}$; tergite 1 (IV) longest, about 2.5 times as long as tergite V; sternite 7 (IX) (Fig. 5G) hemi-membranous, semi-ellipse. Aedeagus (Fig. 5H-J) 0.59 mm long; median lobe dorso-ventrally slightly asymmetric; parameres elongate, broadening to near apices, then greatly narrowed at apices, each paramere with one long apical seta; endophallus composed of numerous spine-like structures, one membranous part, and one forked sclerite.

Female. Unknown.

Comparative notes. The new species is quite distinctive in the form of the male antennal clubs, which leads to a ready separation of $P$. banphabat from all other congeners. Etymology. The new species is named after the type locality, Ban Phabat. The name is a noun in apposition.

Distribution. Laos: Bolikhamsai.

\section{Pselaphodes dalatensis sp. nov.} (Figs 4B, 6)

Type material (1 specimen). Holotype: VIETNAM: LÂM Đồng: đ, 'VIETNAM. Da Lat, Institute of Biology, at light, No. 765., 10.XII.1994, S. Mahunka, Gy. Sziráki \& L. Zombori’ (MHNG).

Diagnosis. Male body length $3.85 \mathrm{~mm}$. Antennomeres 9-11 greatly modified and forming distinct club, antennomere
9 broadly impressed on ventral surface, with short basal protuberance and setose tuft above protuberance, apical margin strongly elevated and expanded to form irregular lamina-like projection, antennomere 10 with mesal margin bluntly projected at base, antennomere 11 strongly constricted at base. Protrochanter with sharp ventral spine at base and tiny ventral tooth near apex, profemur with large triangular ventral projection at middle, protibia with two roundly-triangular projections along mesal margin in apical half; mesotrochanter with acute ventral spine. Hornlike metaventral processes short, in lateral view triangular, narrowing apically. Aedeagus with moderately long parameres; endophallus composed of two elongate sclerites. Female unknown.

Description. Male (Fig. 4B). Body length $3.85 \mathrm{~mm}$. Head approximately as long as wide, HL $0.68 \mathrm{~mm}$, HW 0.70 $\mathrm{mm}$; eyes prominent, each composed of about 45 facets. Antennomeres 2-7 each moniliform, except for antennomere 3 distinctly longer than 2 and 4; antennomeres 9-11 (Fig. 6A) greatly modified, antennomere 9 broadly excavated on ventral surface, with short basal protuberance, apical part strongly elevated and expanded to form irregular lamina-like projection, with setose tuft below projection, antennomere 10 moderately curved in lateral view, its mesal margin bluntly projected at base, antennomere 11 strongly constricted at base. Pronotum (Fig. 6B) slightly longer than wide, PL 0.70 $\mathrm{mm}, \mathrm{PW} 0.67 \mathrm{~mm}$, narrowing apically at apical 2/5. Elytra much broader than long, EL $1.09 \mathrm{~mm}$, EW $1.35 \mathrm{~mm}$. Hornlike metaventral processes (Fig. 6C) short, in lateral view sub-triangular and narrowing apically. Protrochanter (Fig. 6D) with sharp ventral spine at base, and tiny ventral tooth near apex; profemur with large triangular ventral projection at middle; protibia (Fig. 6E) with two roundly-triangular projections along mesal margin in apical half; mesotrochanter (Fig. 6F) with acute ventral spine; mesofemur (Fig. 6F), metatrochanter and metafemur (Fig. 6G) simple. Abdomen broad at base and narrowed posteriorly, AL $1.28 \mathrm{~mm}$, AW $1.28 \mathrm{~mm}$. Aedeagus (Fig. 6H-J) with elongate parameres, each (Fig. 6K) having four thick apical setae; endophallus composed of two elongate sclerites (note: the median lobe of the aedeagus is broken in holotype).

Female. Unknown.

Comparative notes. This is another distinctive species, the male of which can be rather easily distinguished from all congeners by unusual forms of the antennal club and protibia.

Etymology. The new species name, dalatensis $(-i s,-e)$, is a latinized adjective given after the type locality, Da Lat city. Distribution. Vietnam: Lâm Đồng.

\section{Pselaphodes hainanensis Yin \& Li, 2013}

Pselaphodes hainanensis Yin \& Li, 2013 in YIN et al. (2013b: 43)

Type locality. China, Hainan, Baisha County, Yuanmeng, near Yinggezui Station, N1903'10', E109³3'55, $660 \mathrm{~m}$.

Additional material examined (1 specimen). LAOS: HouAPHANH: $1 \hat{\delta}$, 'LAOS-NE, Hua Phan prov., Ban Saluei, Phu Phan Mt., 20¹5'N, $104^{\circ} 02^{\prime} \mathrm{E}, 1500-2000$ m, 26. iv.-11.v. 2001, J. Bezděk leg' (NMPC).

Comments. This species belongs to the P. tianmuensis species group and differs from related species primarily 
in the relatively elongate median lobe of aedeagus. The single male from Laos is morphologically largely identical to those of Hainan, even the positions of the two endophalic sclerites are almost the same.

Distribution. China: Hainan; Laos: Houaphanh (YIN et al. 2013b; this paper). First country record for Laos.

\section{Pselaphodes incisus Huang, Li \& Yin, 2018}

Pselaphodes incisus Huang, Li \& Yin, 2018b: 103

Type locality. China: Yunnan, Xishuangbanna, Menglun, Botanical Garden, $21^{\circ} 55^{\prime} 43^{\prime \prime} \mathrm{N}, 101^{\circ} 15^{\prime} 25^{\prime \prime} \mathrm{E}$, ca. $560 \mathrm{~m}$
Additional material examined (19 specimens). LAOS: AtTAPEU: 9

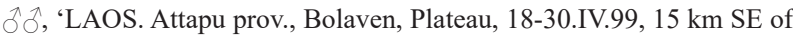

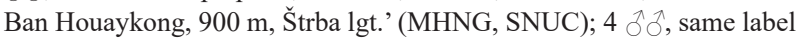
data except 'Nong Lom lake env., 800 m, Jendek \& Šauša' (MHNG). Khammoune: $3 \hat{\delta}$, 'LAOS: Kham Mouan prov., Nakai vill, ca $70 \mathrm{~km}$ NNE Muang Khannouanm 560 m, 7-25.V.2002, Štrba lgt.' (MHNG); 2 $\hat{\partial} \hat{\jmath}$, 'LAOS centr., Khammouan pr., BAN KHOUN NGEUN vill env., 17.v.-6.vi.2007, 300 m, M. Štrba leg.' (MHNG); 1 o, 'LAOS: Khammouan env. Nakai env., $17^{\circ} 43^{\prime} \mathrm{N}, 105^{\circ} 09^{\prime} \mathrm{E}, 22 . v .-8 . v i .2001,500-600 \mathrm{~m}$, Jendek \& Šauša' (MHNG).

Comments. This species was originally described based on material from Yunnan, southwestern China, and Attapeu
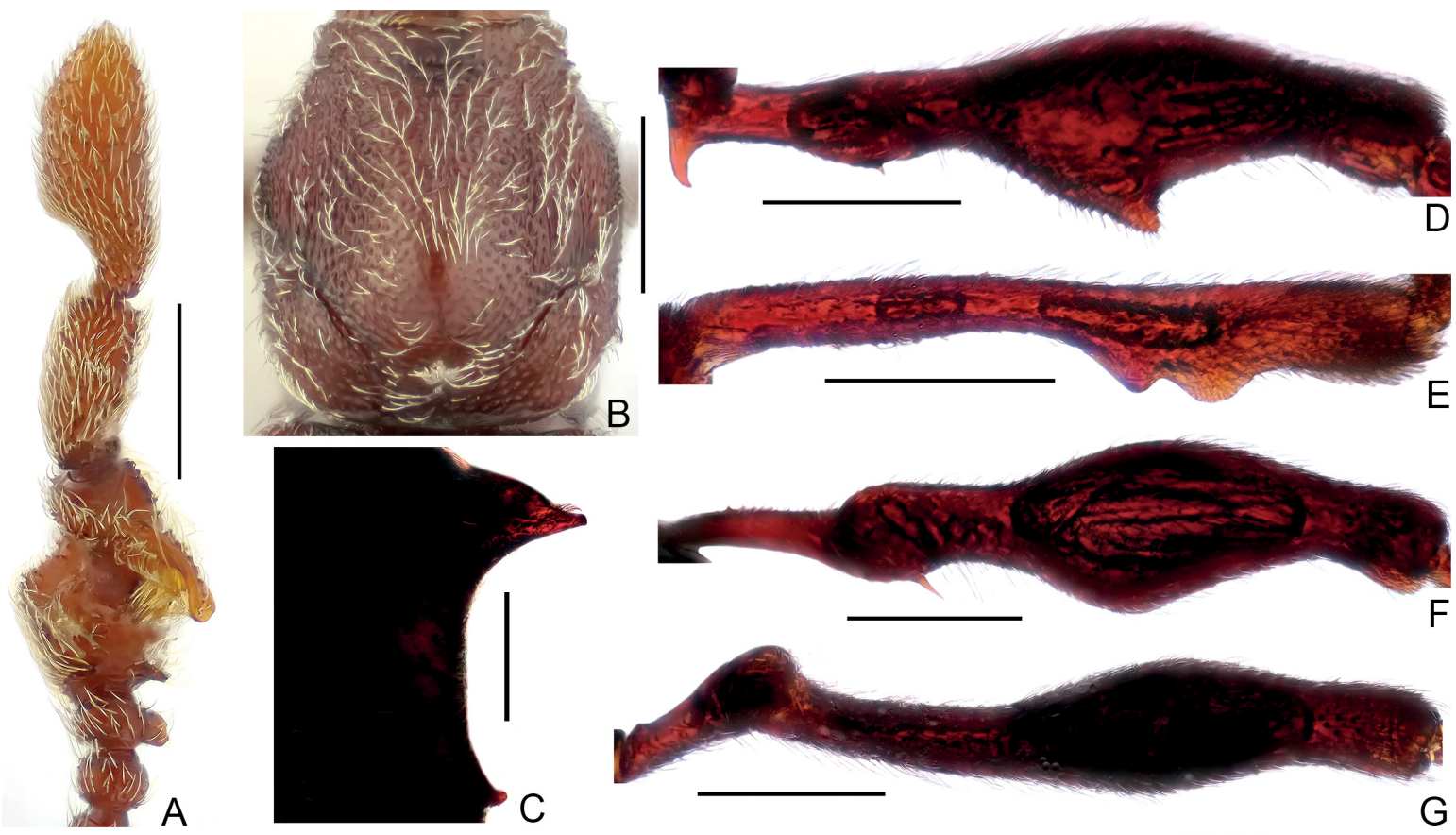

B
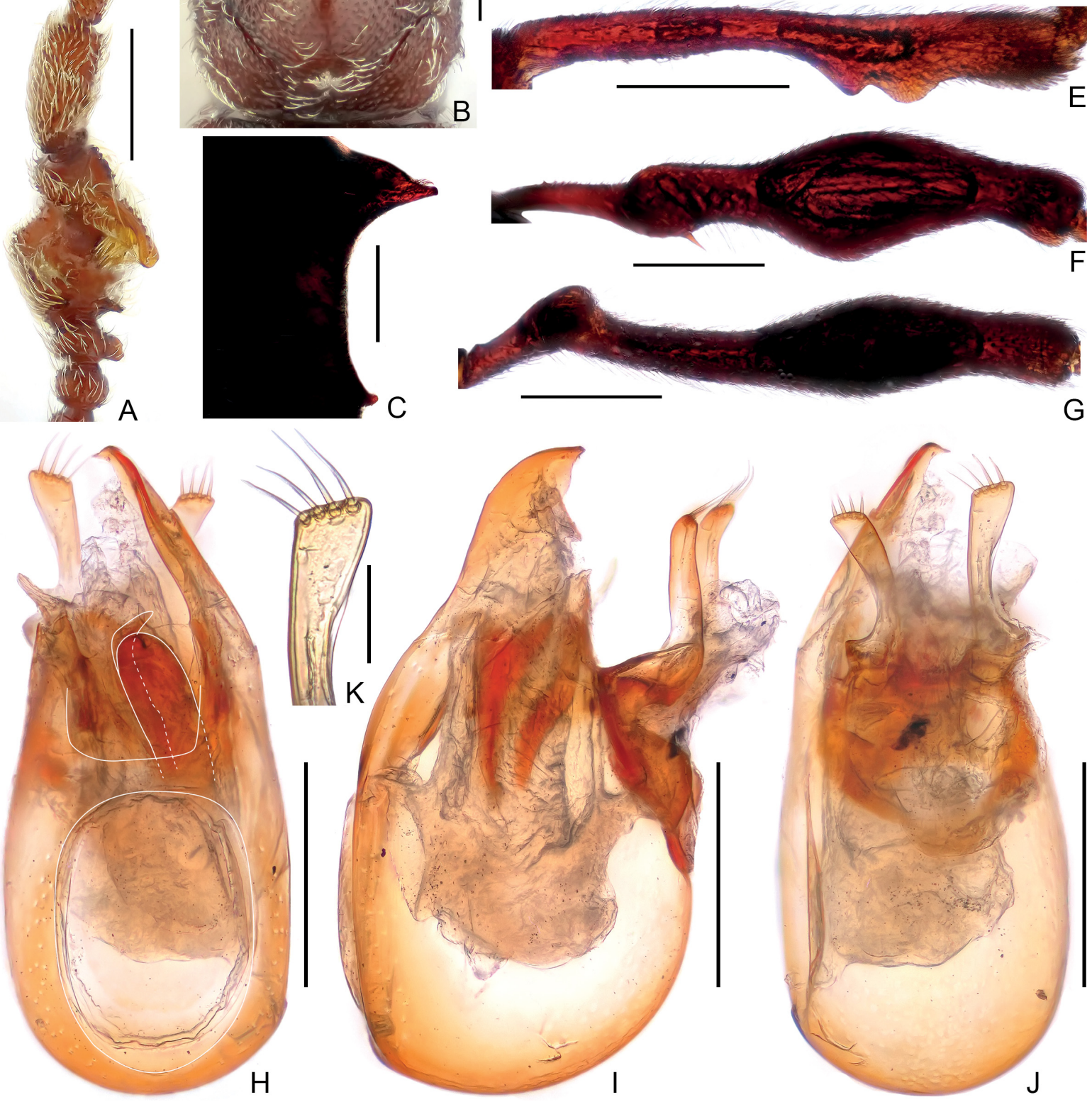

Fig. 6. Male diagnostic features of Pselaphodes dalatensis sp. nov. A - eight antennal club, in ventral view; B - pronotum; C - metaventral process, in lateral view; D - protrochanter and profemur; E - protibia; F - mesotrochanter and mesofemur; G - metatrochanter and metafemur; H-J - aedeagus, in dorsal (H), lateral (I), and ventral (J) view; K - apex of right paramere. Scale bars: $0.3 \mathrm{~mm}$ in A, B, D, E, F, G; 0.2 mm in C, H, I, J; 0.1 mm in K. 
and Vientiane, Laos. Diagnostic characters of this species are oblique antennomeres 10 and 11 of the males, and large transverse expansion of the aedeagal parameres before the apices. The additional material examined extends the distributional range of $P$. incisus to Khammouane Province, central Laos.

Distribution. China: Yunnan; Laos: Vientiane, Attapeu, Khammouane (HuANG et al. 2018b; this paper). First provincial record for Khammouane.

\section{Pselaphodes jendeki sp. nov. (Figs 7A, 8)}

Type material (8 specimens). Holotype: VIETNAM: Lào CAI: 'VIETNAM N $22^{\circ} 20^{\prime} \mathrm{N}, 103^{\circ} 50^{\prime} \mathrm{E}$, SAPA (Lao Cai) 25.5-10.6.1991, leg. E. Jendek' (MHNG). ParatyPes: VIETNAM: Lào CaI: $7 \hat{\delta}$, same label data as for holotype (MHNG, SNUC).

Diagnosis. Male length 3.80-3.85 mm. antennomeres 9-11 each elongate, almost simple, antennomere 9 with small disc-like process near apex. Protrochanter with acute ventral spine, profemur with sharp spine at middle; meso- trochanter with acute ventral spine, mesotibia with small, blunt apical tubercle. Horn-like metaventral processes considerably short, apices truncate and bent downwards. Median lobe of aedeagus asymmetric; parameres short; endophallus composed of three sclerites. Female unknow. Description. Male (Fig. 7A). Body length 3.80-3.85 mm. Head slightly longer than wide, HL $0.68-0.73 \mathrm{~mm}$, HW 0.68-0.70 mm; eyes prominent, each composed of about 40 facets. Antennomeres 2-8 each moniliform, antennomeres 9-11 (Fig. 8A) each strongly elongate and enlarged, antennomere 9 with small disc-like structure near apex. Pronotum (Fig. 8B) approximately as long as wide, PL 0.65-0.68 mm, PW 0.62-0.67 mm, sides narrowing anteriorly at apical two-fifths. Elytra broader than long, EL 1.10-1.20 mm, EW 1.30-1.40 mm. Horn-like metaventral processes (Fig. 8C) short and broad in lateral view, apically bifid, upper apex acute, apex truncate. Protrochanter (Fig. 8D) with thin, acute ventral spine; profemur with sharp ventral spine at middle; mesotrochanter (Fig. 8E) with acute ventral spine, mesofemur simple, mesotibia (Fig. 8F)
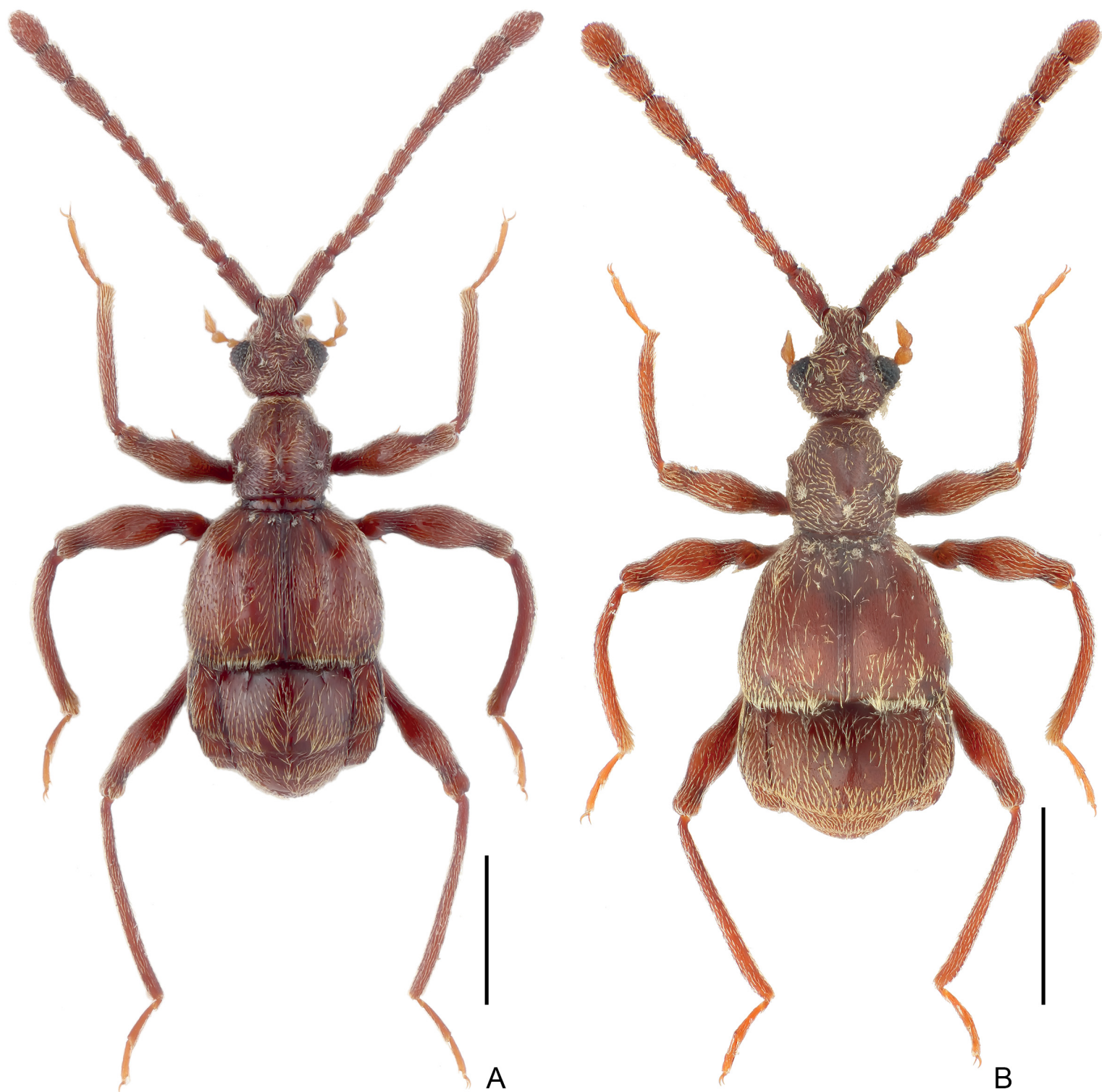

Fig. 7. Dorsal habitus of Pselaphodes males. A - P. jendeki sp. nov.; B - P. nongfa sp. nov. Scale bars: $1 \mathrm{~mm}$. 
with small apical tubercle; metatrochanters and metafemur (Fig. 8G) simple. Abdomen broad at base and narrowed apically, AL 1.15-1.20 mm, AW $1.30 \mathrm{~mm}$. Sternite 7 (IX) (Fig. 8H) hemi-membranous. Aedeagus (Figs 8I-K) 0.75 $\mathrm{mm}$ long, median lobe asymmetric dorso-ventrally, narrowing apically and curved rightwards at apex in dorsal view; parameres much shorter than median lobe, each with three apical setae, endophallus composed of one triangle and two slightly curved, elongate sclerites.

Female. Unknown.

Comparative notes. This species belongs to the $P$. tianmuensis species group whose males share almost simple antennal clubs except for antennomere 9 which has a disc-like process near the apex. The new species may be readily separated from allied species by short and truncate horn-like metaventral processes, unique configuration of the aedeagus, as well as by its distribution.
Etymology. The new species is named after the Slovak entomologist Eduard Jendek, collector of the holotype. Distribution. Vietnam: Lào Cai.

\section{Pselaphodes linae Yin \& Li, 2012}

Pselaphodes linae Yin \& Li, 2012 in YIN et al. (2012: 76)

Type locality. China: Hainan Prov., Wuzhishan Mt., Guzhandao, $18.86657^{\circ} \mathrm{N}, 109.68285^{\circ} \mathrm{E}$, ca. $640 \mathrm{~m}$.

Additional material examined (4 specimens). VIETNAM: HòA BìnH: 3 ổ, 'Vietnam, Hoa binh, 4.-7.6.1986, Ha son binh prov. Jan Horák lgt' (NMPC); 1 §’, 'TOKIN, RĖGION DE HOA-BINH / MUÉSUM PARIS, 1933, A. de COOMAN' (MHNG).

Comments. Pselaphodes linae was originally described from Hainan and Fujian, southern China and later reported from Taiwan. Here it is recorded from northern Vietnam for the first time. This species is readily recognizable by the deeply emarginate ventral and lateral surfaces of an-

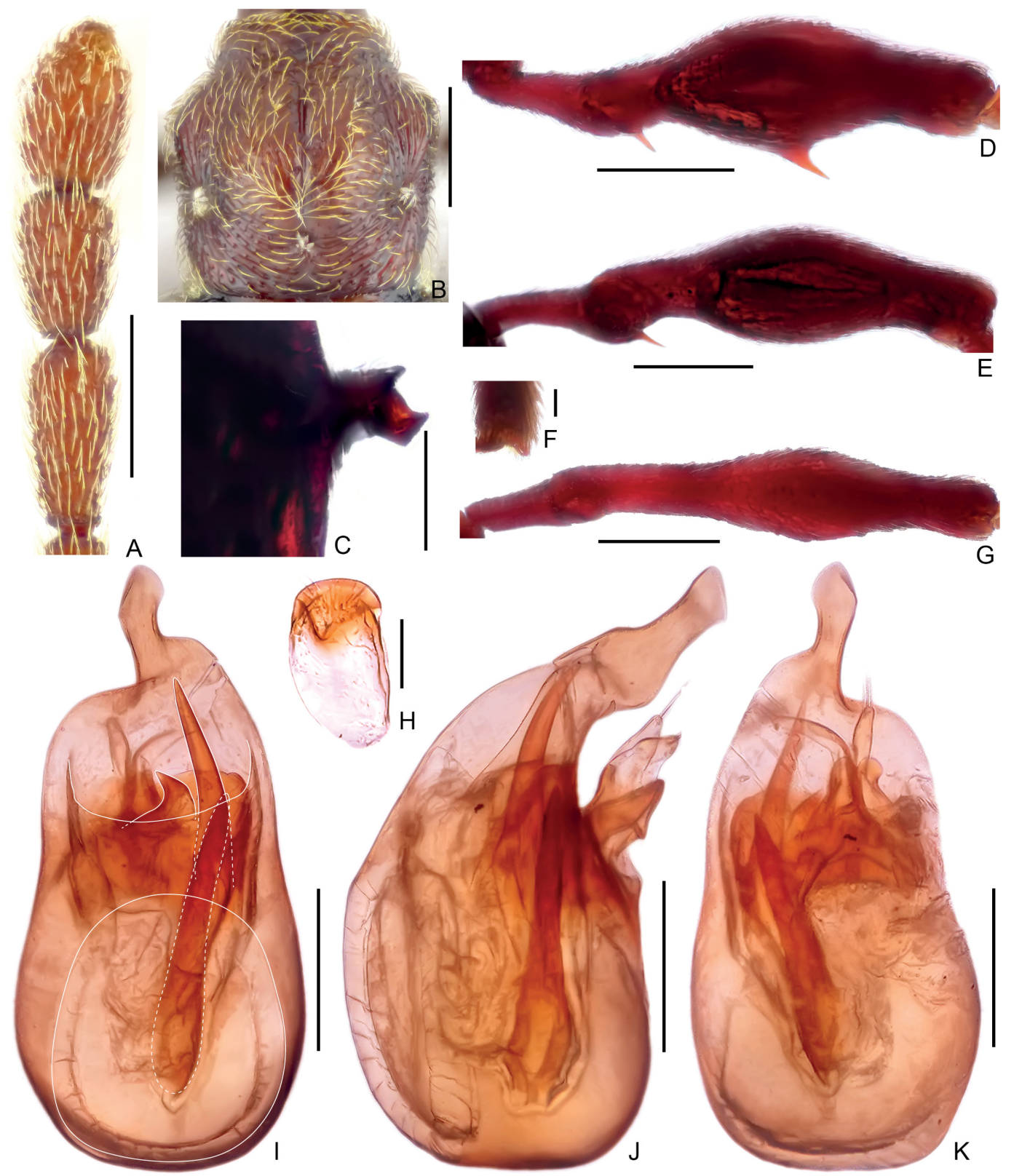

Fig. 8. Male diagnostic features of Pselaphodes jendeki sp. nov. A - left antennal club, in dorsal view; B - pronotum; C - metaventral process, in lateral view; D - protrochanter and profemur; E - mesotrochanter and mesofemur; F - apex of mesotibia; $\mathrm{G}$ - metatrochanter and metafemur; $\mathrm{H}$ - sternite 7 (IX); I-K - aedeagus, in dorsal (I), lateral (J), and ventral (K) view. Scale bars: $0.3 \mathrm{~mm}$ in A, B, D, E, G; $0.2 \mathrm{~mm}$ in C, I, J, K; $0.1 \mathrm{~mm}$ in H; 0.05 mm in F. 
tennomeres 11 and 10 , respectively, presence of a highly raised disc-like projection near the apex of antennomere 9 , and metatibia with an acute tooth at apical 1/3. The male from Vietnam shows little morphological variation in both external features and aedeagus.

Distribution. China: Fujian, Hainan, Taiwan; Vietnam: Hòa Bình (YIN et al. 2012, 2013a; this paper). First country record for Vietnam.

\section{Pselaphodes nongfa sp. nov.}

(Figs 7B, 9)

Type material (1 specimen). HoLOTYPE: LAOS: ATtAPEU: 'LAOS, ATTAPEU prov. Annam Highlands Mts. Dong Amphan NBCA, ca. 1160 m, NONG FA [crater lake], env. $15^{\circ} 05.9^{\prime} \mathrm{N}, 17^{\circ} 25.6^{\prime} \mathrm{E}$, Jiří Hájek leg. 30.iv.-6.v.2010' (NMPC).
Diagnosis. Male length $3.05 \mathrm{~mm}$. Antennomeres 9-11 distinctly elongate and enlarged, lacking modification. Horn-like metaventral processes long and broad at apices. Protrochanter with blunt ventral projection, profemur roundly angulate at middle, protibia with distinct apical protuberance; mesotrochanter bluntly protuberant. Median lobe of aedeagus almost symmetric dorso-ventrally; parameres elongate and slender; endophallus composed of 13 sclerites. Female unknown.

Description. Male (Fig. 7B). Body length $3.05 \mathrm{~mm}$. Head slightly longer than wide, HL $0.61 \mathrm{~mm}$, HW $0.58 \mathrm{~mm}$; eyes prominent, each composed of about 38 facets. Antennomeres 2-8 similarly moniliform; antennomeres 9-10 each elongate, antennomere 10 truncate at base and with round
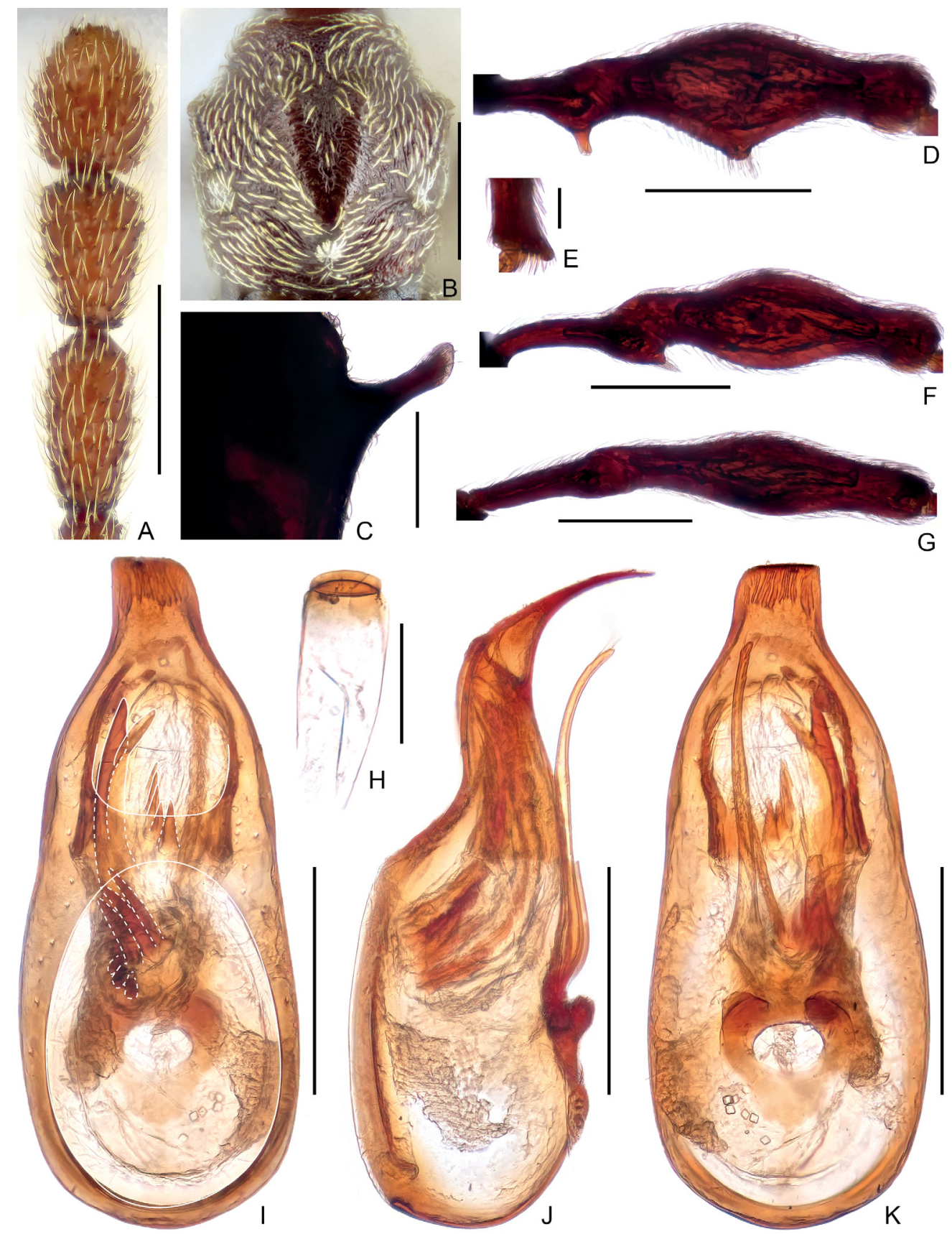

Fig. 9. Male diagnostic features of Pselaphodes nongfa sp. nov. A - left antennal club, in dorsal view; B - pronotum; C - metaventral process, in lateral view; D - protrochanter and profemur; E - apex of protibia; F - mesotrochanter and mesofemur; $\mathrm{G}$ - metatrochanter and metafemur; $\mathrm{H}$ - sternite 7 (IX); $\mathrm{I}-\mathrm{K}$ - aedeagus, in dorsal $(\mathrm{I})$, lateral $(\mathrm{J})$, and ventral $(\mathrm{K})$ view. Scale bars: $0.3 \mathrm{~mm}$ in A, B, D, F, G; $0.2 \mathrm{~mm}$ in C, I, J, K; $0.1 \mathrm{~mm}$ in H; $0.05 \mathrm{~mm}$ in E. 
apex, together they forming distinct club (Fig. 9A), which lacks modification. Pronotum (Fig. 9B) slightly longer than wide, PL $0.62 \mathrm{~mm}$, PW $0.58 \mathrm{~mm}$, with lateral margins slightly expanding and then narrowing anteriorly at apical third. Elytra much broader than long, EL $0.80 \mathrm{~mm}$, EW 1.10 $\mathrm{mm}$; disc with linear microsculpture. Horn-like metaventral processes (Fig. 9C) elongate, in lateral view broadened at apex. Protrochanter (Fig. 9D) with blunt ventral protuberance; profemur roundly protuberant at middle; protibia (Fig. 9E) with large apical tubercle; mesotrochanter (Fig. 9F) with roundly triangular ventral projection; mesofemur (Fig. 9F), metatrochanter and metafemur (Fig. 9G) simple. Abdomen broad at base and narrowed apically, AL 0.92 mm, AW 1.12 mm. Sternite 7 (IX) (Fig. 9H) elongate, hemi-membranous. Aedeagus (Figs 9I-K) $0.60 \mathrm{~mm}$ long, almost symmetric dorso-ventrally; median lobe broad at base and narrowing apicad; parameres each elongate and slender (right paramere); with two short preapical setae; endophallus composed of six short sclerites at base, five similar ones at middle, and two elongate sclerites on the left side.

Female. Unknown.

Comparative notes. The new species is most similar to P. maolanensis Huang, Li \& Yin, 2018 from Guizhou, southwestern China by sharing many external features. The male of these two species can be readily separated by relatively much more elongate antennomere 10 in relation to antennomeres 9 and 11, the narrow apical half of the aedeagus, as well as the more complex structure of endophallus of $P$. nongfa sp. nov.

Etymology. The new species is named after its type locality, Nong Fa Lake (Blue Lake). The name is a noun in apposition.

\section{Distribution. Laos: Attapeu.}
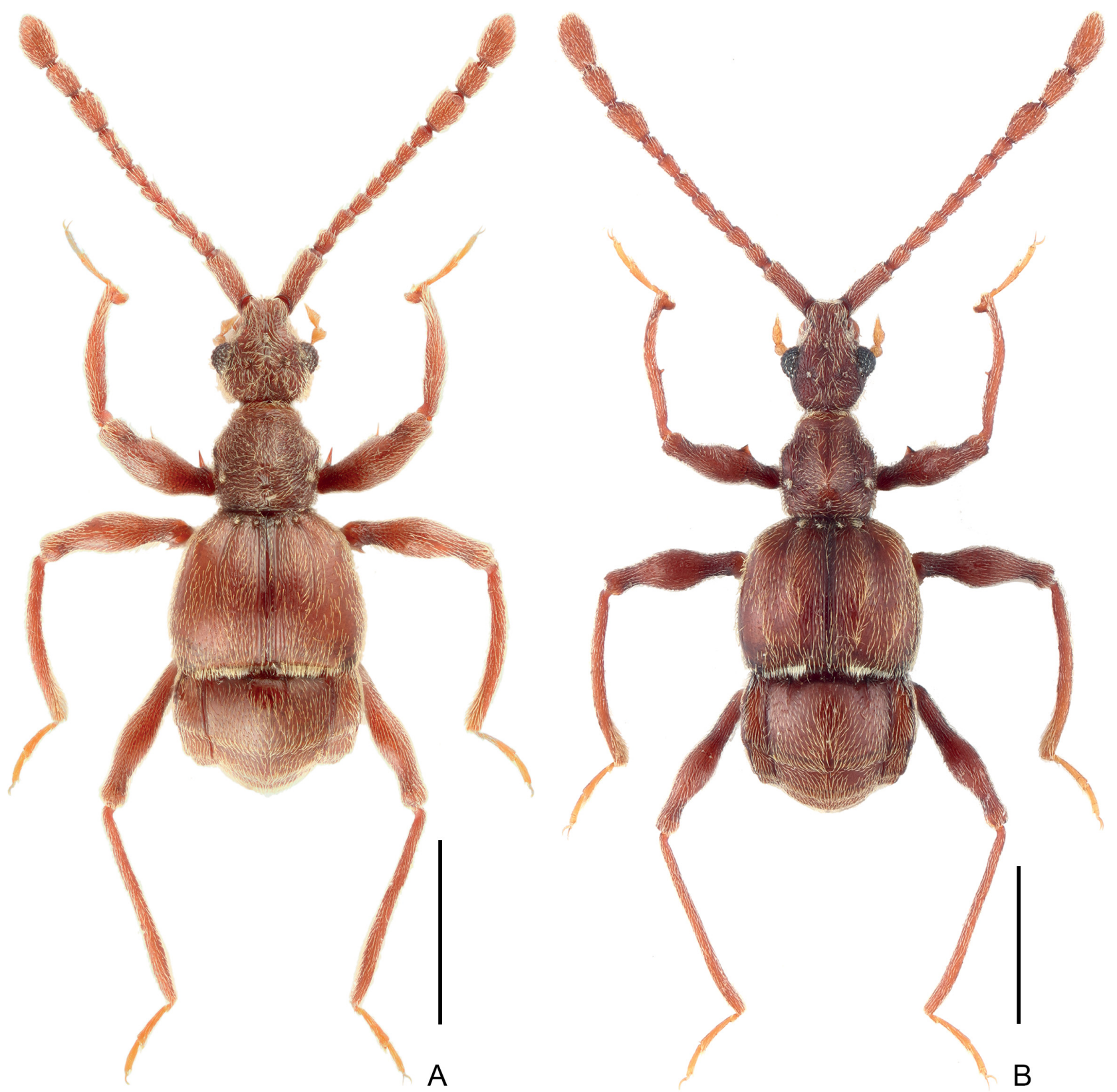

Fig. 10. Dorsal habitus of Pselaphodes males. A - Pselaphodes olexai sp. nov.; B - Pselaphodes parapectinatus sp. nov. Scale bars: $1 \mathrm{~mm}$. 


\section{Pselaphodes olexai sp. nov.}

(Figs 10A, 11)

Type material (1 specimen). Holotype: VIETNAM: $\hat{\alpha}$, 'Tam Dao, 20-27.6, N. VIETNAM, A. Olexa, 1990’ (MHNG).

Diagnosis. Male length $3.08 \mathrm{~mm}$. Antennomere 9-11 elongate and forming distinct club, antennomere 9 with large disc-like protuberance near apex. Protrochanter with hook-like ventral spine, profemur strongly expanded at middle, with long, thin ventral spine, protibia with broad and apically truncate projection; mesotrochanter with acute ventral spine. Horn-like metaventral processes short and apically blunt. Median lobe of aedeagus asymmetric, narrowing and curved rightwards at apex in dorsal view; parameres broad; endophallus composed of two elongate sclerites. Female unknown.

Description. Male (Fig. 10A). Body length $3.08 \mathrm{~mm}$. Head slightly wider than long, HL $0.56 \mathrm{~mm}$, HW 0.59 $\mathrm{mm}$; eyes prominent, each composed of about 42 facets. Antennomeres 2-8 similarly moniliform, antennomeres 9-11 (Fig. 11A) forming distinct club, antennomere 9 with large disc-like protuberance near apex, antennomere 10 subcylindrical, antennomere 11 sub-oval, narrowing from

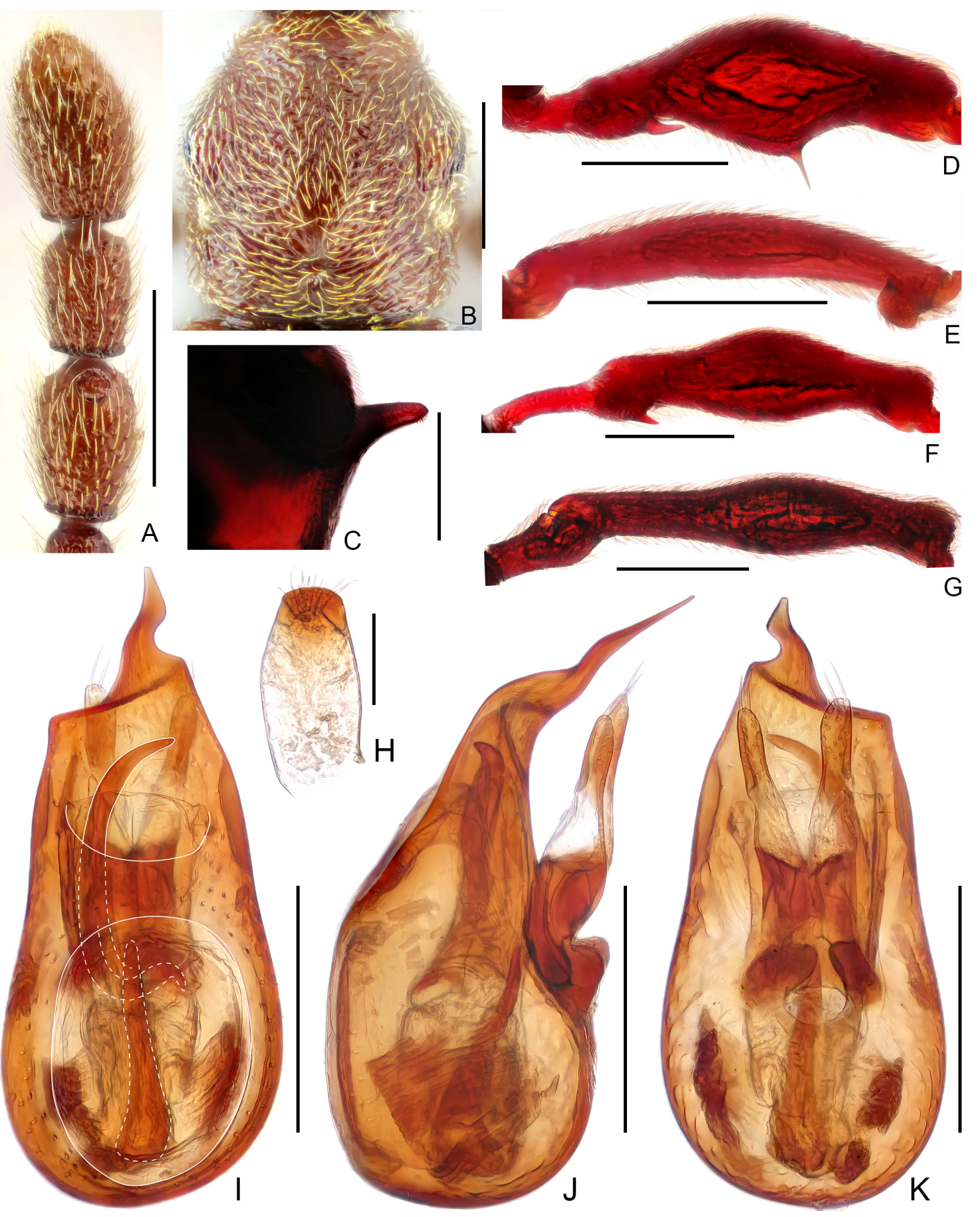

Fig. 11. Male diagnostic features of Pselaphodes olexai sp. nov. A - left antennal club, in lateral view; B - pronotum; C - metaventral process, in lateral view; D - protrochanter and profemur; E - protibia; F - mesotrochanter and mesofemur; $\mathrm{G}$ - metatrochanter and metafemur; $\mathrm{H}$ - sternite 7 (IX); I-K aedeagus, in dorsal (I), lateral (J), and ventral (K) view. Scale bars: $0.3 \mathrm{~mm}$ in A, B, D, E, F, G; $0.2 \mathrm{~mm}$ in C, I, J, K; $0.1 \mathrm{~mm}$ in H. 
middle toward apex. Pronotum (Fig. 11B) slight longer than wide, PL $0.61 \mathrm{~mm}$, PW $0.57 \mathrm{~mm}$, with lateral margins rounded and narrowing apically at apical 1/3. Elytra much broader than long, EL $0.81 \mathrm{~mm}$, EW $1.10 \mathrm{~mm}$. Horn-like metaventral processes (Fig. 11C) short and straight, blunt at apices. Protrochanter (Fig. 11D) with hook-like ventral spine, profemur strongly expanded and with acute and long ventral spine near middle, protibia (Fig. 11E) with large, apically truncate projection before apex; mesotrochanter (Fig. 11F) with short ventral spine; mesofemur (Fig. 11F), metatrochanter and metafemur (Fig. 11G) simple. Abdo- men broad at base and narrowed apically, AL and AW 1.0 mm. Sternite 7 (IX) (Fig. 11H) hemi-membranous, roundly elongate. Aedeagus (Figs 11I-K) $0.55 \mathrm{~mm}$ long, median lobe asymmetric dorso-ventrally, narrowing and curved rightwards at apex in dorsal view; parameres each with two long and two short apical setae; endophallus with one elongate sclerites at middle and another elongate one at base.

Female. Unknown.

Comparative notes. Antennomere 9 with a distinct disclike protuberance, thickened protibia with a large, apically truncate projection, and broad profemur of the male
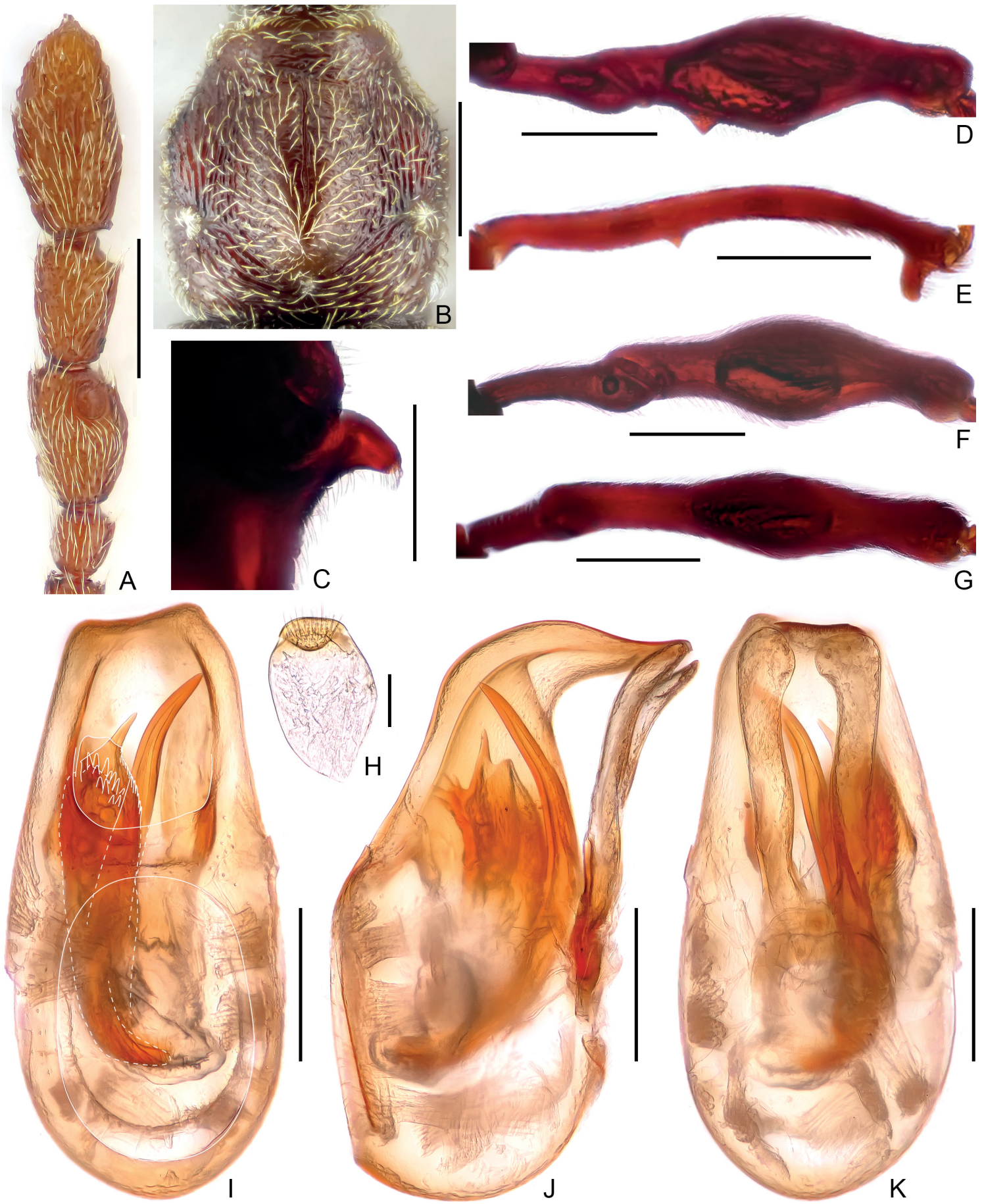

Fig. 12. Male diagnostic features of Pselaphodes parapectinatus sp. nov. A - left antennal club, in lateral view; B - pronotum; C-metaventral process, in lateral view; D - protrochanter and profemur; E - protibia; F - mesotrochanter and mesofemur; $\mathrm{G}$ - metatrochanter and metafemur; $\mathrm{H}$ - sternite 7 (IX); I-K - aedeagus, in dorsal (I), lateral (J), and ventral (K) view. Scale bars: $0.3 \mathrm{~mm}$ in A, B, D, E, F, G; 0.2 mm in C, I, J, K; $0.1 \mathrm{~mm}$ in H. 
collectively provide a ready separation of $P$. olexai sp. nov. from all known congeners.

Etymology. The new species is named after the Czech entomologist Aldo Olexa, collector of the holotype. Distribution. Northern Vietnam.

\section{Pselaphodes paraculeus Huang, Li \& Yin, 2018}

Pselaphodes paraculeus Huang, Li \& Yin, 2018a: 468

Type locality. China: Guangxi, Wuming County, Daming Shan, $23^{\circ} 28^{\prime} 44^{\prime \prime} \mathrm{N}, 108^{\circ} 26^{\prime} 06^{\prime \prime} \mathrm{E}, 1500 \mathrm{~m}$.

Additional material examined (1 specimen). LAOS: BoLIKHAMSAI: 1 ô, 'LAOS, 1-18.v.2001, Bolikhamxai prov., $18^{\circ} 21^{\prime} \mathrm{N}, 105^{\circ} 08^{\prime} \mathrm{E}$, Ban Nape (8 km NE), 600 m, V. Kubáń leg' (MHNG).

Comments. Pselaphodes paraculeus was originally described from Guangxi and Guizhou, southern China, and is here newly record from Bolikhamsai, central Laos. This species is externally similar to P. aculeus Yin, Li \& Zhao, 2010, which is widely distributed in China, but can be separated from the latter by the median lobe of aedeagus with a round, rather than deeply concave, apex. Compared to that from Guangxi, the male from Laos shows little variation in the shape of aedeagus.

Distribution. China: Guangxi, Guizhou; Laos: Bolikhamsai (HuANG et al. 2018; this paper). First country record for Laos.

\section{Pselaphodes parapectinatus sp. nov. (Figs 10B, 12)}

Type material (11 specimens). HOLOTYPE: VIETNAM: LÀo CAI: ^ֶ, 'VIETNAM N, 22'20'N, 103'50'E, SAPA (Lao Cai) 25.5-10.6.1991, leg. E. Jendek' (MHNG). PARATYPES: VIETNAM: LÀO CAI: $9 \hat{\delta} \hat{\delta}$, same label data as for holotype (MHNG, SNUC); 1 o' '[N-Vietnam], 23.v.1998 / Mt. Phang Si Pang (1,840, beating), Lao Cai Prov.' (MHNG).

Diagnosis. Male length 3.23-3.28 mm. Antennomeres 9-11 greatly elongate and forming distinct club, antennomere 9 with large disc-like process near apex. Horn-like metaventral processes short and apically blunt. Profemur with ventral spine before middle expansion; protibia strongly curved, with small middle spine and large apical projection. Median lobe of aedeagus almost symmetric dorso-ventrally; parameres long and broad; endophallus composed of broad, plate-like structure and elongate sclerite. Female unknow.

Description. Male (Fig. 10B). Body length 3.23-3.28 $\mathrm{mm}$. Head slightly longer than wide, HL $0.65-0.70 \mathrm{~mm}$, HW $0.63 \mathrm{~mm}$; eyes prominent, each composed of about 42 facets. Antennomeres $2-8$ of similar form, each slightly longer than wide, antennomeres 9-11 (Fig. 12A) each much longer than wide, antennomere 9 with distinct disclike process near apex, antennomere 10 subcylindrical, slightly broadened from base toward apex, antennomere 11 sub-oval, narrowing apically. Pronotum (Fig. 12B) approximately as long as wide, PL $0.63-0.65 \mathrm{~mm}$, PW $0.60-0.63 \mathrm{~mm}$, sides roundly narrowing apically at apical 2/5. Elytra slightly longer than wide, EL $0.93-0.95 \mathrm{~mm}$, EW 0.90 mm. Horn-like metaventral processes (Fig. 12C) in lateral view roundly triangular, short and blunt at apices. Profemur (Fig. 12D) with triangular spine at basal 1/3, angularly expanded at middle; protibia (Fig. 12E) strongly curved in apical half, with small spine near middle and large apical projection; mesotrochanter, mesofemur (Fig. 12F), metatrochanter and metafemur (Fig. 12G) simple. Abdomen broad at base and narrowed posteriorly, AL 0.90-0.95 mm, AW 1.08-1.15 mm; tergite 1 (IV) longest, more than twice as long as tergite V; sternite 7 (IX) (Fig. 12H) hemi-membranous, suboval. Aedeagus (Figs 12I-K) $0.76 \mathrm{~mm}$ long; median lobe nearly symmetric dorso-ventrally; parameres each elongate and broad, with enlarged, round apices; endophallus comprising one plate-like sclerite with many small spines at apex, and one elongate, curved sclerite.

Female. Unknown.

Comparative notes. The new species is most similar to P. pectinatus Yin, Li \& Zhao, 2011 from Hainan, southern China, by sharing similar position and structure of the leg modifications, and short horn-like metaventral processes of the male. These two species differ in the presence of a large disc-like process on antennomere 9 (process lacking in $P$. pectinatus), a much shorter and differently shaped apical projection of protibia, each paramere of aedeagus lacking the apical setae and roundly broadened at the apex (each paramere with many thick apical and preapical setae, and rounded but not broadened at the apex in P. pectinatus), and different structure of the endophallic sclerites of $P$. parapectinatus sp. nov.

Etymology. The new specific name reflects the morphological similarity between the new species and P. pectinatus. The name consists of the Greek prefix pará- (beside; next to, near, from) and the Latin adjective pectinatus (-a, -um; meaning combed).

Distribution. Vietnam: Lào Cai.

Taiwanophodes magnus Bekchiev, 2010

Taiwanophodes magnus Bekchiev, 2010: 183.

Type locality. N. Vietnam, 180 km SSW. Hanoi, 40 km SE. Thanh Hóa, Ben En Nat. Park, alt. $50 \mathrm{~m}$.

Additional material examined (7 specimens). VIETNAM: NINH BìnH: $4 \hat{\delta}$, 'VIETNAM N, $100 \mathrm{~km}$ s from Hanoi CUC-PHUONG nat. Park, 02.-12.5.1991, leg. E. Jendek' (VBGG, SNUC). Lào CAI: 1 ภै, 'VIETNAM N $22^{\circ} 20^{\prime} \mathrm{N}, 103^{\circ} 50^{\prime} \mathrm{E}$, SAPA (Lao Cai) 25.5.-10.6.1991, leg. E. Jendek (VBGG)'; Yên Bár: 1 đ̊, 'N-VIETNAM, Yen Bai, V.90, Dembicky leg. (VBGG). LAOS: BoLIKHAMSAI: 1 o, 'LAOS, 1-18.v.2001, Bolikhamxai prov., $18^{\circ} 21^{\prime} \mathrm{N}, 105^{\circ} 08^{\prime} \mathrm{E}$, Ban Nape ( $\left.8 \mathrm{~km} \mathrm{NE}\right), \sim 600 \mathrm{~m}$, V. Kubáñ leg' (MHNG).

Distribution. Vietnam: Thanh Hóa, Ninh Bình, Lào Cai, Yên Bái; Laos: Bolikhamsai (BEKCHIEv 2010; this paper). First provincial record for Yên Bái, and first country record for Laos.

Comments. Taiwanophodes magnus was originally described from northern Vietnam, and it is here recorded from a few new localities in Vietnam, as well as from Laos for the first time. The male of this species is easily recognizable by unique structure of the antennal club, with antennomere 10 broadly excavated on the mesal surface and with a large projection at the apex, and antennomere 11 strongly constricted at the base, protibia has a large blunt protuberance near the apex, and endophallus of aedeagus is composed of a membranous structure plus an elongate sclerite on the right side. 


\section{Key to males of the Pselaphodes complex from Vietnam and Laos}

1 Maxillary palpi small, palpomeres 3-4 symmetric, lacking tubercle or expansion on lateral margins. .... 2

- Maxillary palpi much larger, palpomeres 3-4 asymmetric, with tubercle or expansion on lateral margins. ... 7

2 Pronotum lacking antebasal sulcus (BEKCHIEv et al. 2013: fig. 1). Lasinus Sharp, 1874.

Lasinus mandarinus Raffray, 1890

- Pronotum with antebasal sulcus connecting lateral antebasal foveae. Paralasinus Hlaváč \& Nomura, 2001 (couplets 3-6 adopted from HLaváč \& NomURA 2001). ... 3

3 Head regularly narrowed anteriad without constriction. ... 4

- Head strongly constricted and impressed at anterior margin of eyes. ....................................................... 5

4 Scape long, 4.5 times as long as wide (HLAvéč \& NomURA 2001: fig. 2A); each mesotrochanter with one small spine close to apex, mesofemur with small spine at basal third; horn-like metaventral processes conical.

.. Paralasinus antennatus Hlaváč \& Nomura, 2001

- Scape short, at most 4 times as long as wide (HLAvéČ \& NoMURA 2001: fig. 2B); mesotrochanter with two spines, mesofemur lacking spine; horn-like metaventral processes prominent, with tip oriented towards abdomen.

Paralasinus thayerae Hlaváč \& Nomura, 2001

5 Antennomere 9 short and large, no more than 1.5 times as long as wide (Hlaváč \& Nomura 2001: fig. 2D); mesotrochanter with one apical spine.

Paralasinus humilis Hlaváč \& Nomura, 2001

- Antennomeres 9 long and slender, distinctly more than twice as long as wide; mesotrochanter with two spines.

6 Scape relatively long, 4.5 times as long as wide and 5 times as long as pedicel (HLAVÁČ \& NomURA 2001: fig. 2C).

Paralasinus gigas Hlaváč \& Nomura, 2001

- Scape relatively short, 3.5 times as long as wide and 3.6 times as long as pedicel (HLAvíč \& Nomura 2001: fig. 2E). ........... Paralasinus namcatienicus Hlaváč \& Nomura, 2001

7 Tarsomeres 2 greatly extending beneath, and reaching more than half length of tarsomeres 3 ............. 8 Tarsomeres 2 normal, not extending beneath tarsomeres 3 .

8 Pronotum with complete antebasal sulcus connecting median and lateral antebasal foveae, apical portion lacking modification (BEKCHIEv 2010: fig. 1). Taiwanophodes Hlaváč, 2003.

Taiwanophodes magnus Bekchiev, 2010

- Pronotum lacking antebasal sulcus, apical portion with modification. Nomuraius Hlaváč, 2003 (couplet 9 adopted from HuANG \& YIN 2018). ...................... 9

9 Head with broad, deep cavity on posterior half (YIN \& LI 2013b: fig. 1A); antennomere 9 much longer than 10 (YIN \& LI 2013b: fig. 2A); pronotum strongly modified in anterior portion (YIN \& LI 2013b: fig. 2B); metatibia simple, not expanded mesally.

Nomuraius piaoacus Yin \& Li, 2013

- Head weakly concave at posterior margin (YIN \& LI 2013b: fig. 4A); antennomere 9 slightly longer than 10 (YIN \& Li 2013b: fig. 5A); pronotum slightly modified in anterior portion (YIN \& Li 2013b: fig. 5B); metatibia expanded mesally near apex (YIN \& LI 2013b: fig. 5H)............. Nomuraius vietnamicus Hlaváć, 2003

10 Head with indistinct vertexal and frontal foveae; head and pronotum with dense and coarse punctation (YIN \& Li 2013a: fig. 4A). Linan Hlaváč, 2003. ...... Linan fortunatus Yin \& Li, 2013

- Head with distinct vertexal and frontal foveae; head and pronotum finely punctate. ........................... 11

11 Metaventral fovea present. Labomimus Sharp, 1883. ........................................................... 12

- Metaventral fovea absent. Pselaphodes Westwood, 1870 16

12 Antennomere 9 with disc-like process near or on apex; antennomere 11 curved in middle or at base. ......... 13

- Antennomere 9 lacking disc-like process; antennomere 11 not curved. 14

13 Antennomere 9 greatly broadened, disc-like process occupying more than $4 / 5$ of antennal width, antennomere 10 slightly elongate, antennomere 11 curved at base (YIN et al. 2013a: fig. 3); horn-like metaventral processes relatively long (YIN et al. 2013a: fig. 5); metacoxa lacking ventral protuberance.

Labomimus bannaus Yin \& Li, 2013

- Antennomere 9 slightly broadened at apex, disc-like process much smaller, antennomere 10 distinctly elongate, subcylindrical, antennomere 11 curved in middle (ZHANG et al. 2019: fig. 14A); horn-like metaventral processes relatively short (ZHANG et al. 2019: fig. 14C); metacoxa with triangular ventral protuberance (ZHANG et al. 2019: fig. 14G).

Labomimus maolan Zhang, Li \& Yin, 2019

14 Antennomere 9 with angulate process on anteromesal margin (YIN et al. 2012: fig. 4A).

Labomimus shii (Yin \& Li, 2012)

- Antennomere 9 lacking an angulate process on anteromesal margin. 15

15 Size larger, body length $3.09-3.23 \mathrm{~mm}$; antennomeres 9-11 each impressed or excavated on dorsal or ventral surface (Fig. 2A); aedeagus with median lobe asymmetrical dorso-ventrally (Figs 2I, K).

Labomimus cavicornis sp. nov.

- $\quad$ Size smaller, body length $2.84 \mathrm{~mm}$; antennomere 9 with round cavity near apex, antennomere 10 strongly constricted at base to form nodule, antennomere 11 unmodified (Fig. 3A); aedeagus with median lobe symmetrical dorso-ventrally (Figs $3 \mathrm{H}, \mathrm{J}$ ).

Labomimus cucphuong sp. nov.

16 Antennomeres 9-11 simple, lacking modification (Fig. 9A). ................. Pselaphodes nongfa sp. nov.

- Antennomeres 9-11 with at least one antennomere modified. 
17 Antennomere 9 lacking disc-like process/projection. ... 18

- Antennomere 9 with disc-like process/projection. .... .20

18 Antennomere 9 and 10 obliquely constricted at apex and at base, respectively (HuANG et al. 2018b: fig. 4A); aedeagus with parameres each transversely expanded before apex, then with one elongate process on apical margin of each expansion, with two short preapical and two long apical setae at apex of process (HuANG et al. 2018: figs. 4I-K).

Pselaphodes incisus Huang, Li \& Yin, 2018

- Antennomere 9 and 10 not modified as in P. incisus; aedeagus with parameres lacking transverse expansion before apex. 19

19 Size much smaller, body length $3.05 \mathrm{~mm}$; antennomeres 9 and 10 each with small tubercle at apex and at base, antennomere 11 truncate at base (Fig. 5A); protibia simple. .... Pselaphodes banphabat sp. nov. - Size much larger, body length $3.85 \mathrm{~mm}$; antennomere 9 strongly excavated on mesal surface, apical portion forming irregular lamina-like projection, antennomere 10 moderately curved in lateral view, with mesal margin projected at base, antennomere 11 strongly constricted at base (Fig. 6A); protibia with two roundly triangular projections on ventral margin on apical half (Fig. 6E).

Pselaphodes dalatensis sp. nov.

20 Metatibia either with small spine at apical $1 / 3$ or with preapical setose tuft. .......................................... 21

- Metatibia simple, lacking modification. .............. 22

21 Antennomere 10 with lateral surface impressed in middle, antennomere 11 slightly curved (YIN et al. 2012: fig. 2A); protibia somewhat sinuate, lacking protuberance in middle (YIN et al. 2012: fig. 1), mesotrochanter with tiny ventral spine (YIN et al. 2012: fig. 2E). ............ Pselaphodes linae Yin \& Li, 2012

- Antennomere 10-11 neither impressed nor curved (HUANG et al. 2018a: fig. 12A); protibia almost straight, with triangular protuberance in middle (HUANG et al. 2018a: fig. 12E), mesotrochanter with large ventral spine (HuANG et al. 2018a: fig. 12F).

... Pselaphodes paraculeus Huang, Li \& Yin, 2018

22 Protibia with large projection before apex. ......... 23

Protibia lacking projection. ................................ 24

23 Protibia broadened throughout, slightly curved, lacking tooth before middle, preapical projection broad and truncate (Fig. 11E); mesotrochanter with acute short ventral spine (Fig. 11F).

Pselaphodes olexai sp. nov.

- Protibia not broadened, strongly curved in apical half, with triangular tooth before middle, preapical projection elongate, with blunt apex (Fig. 12E); mesotrochanter lacking spine on ventral margin (Fig. 12F). ............ Pselaphodes parapectinatus sp. nov.

24 Antennomere 10 with thin, elongate protuberance at base (BEKCHIEV et al. 2019: fig. 3a).

... Pselaphodes fansipanensis Bekchiev \& Yin, 2019

- Antennomere 10 lacking protuberance at base. ... 25
25 Horn-like metaventral processes relatively short, in lateral view apically bifid, upper apex acute, lower apex truncate (Fig. 8C); median lobe of aedeagus less extended, endophallus composed of one triangular and two markedly elongate sclerites (Fig. 8I-K). .....

Pselaphodes jendeki sp. nov.

- Horn-like metaventral processes relatively long, in lateral view straight, with acute apex (YIN et al. 2013b: fig. 12C); median lobe of aedeagus much more extended, endophallus composed of two elongate sclerites (YIN et al. 2013b: fig. 12I, K).

Pselaphodes hainanensis Yin \& Li, 2013

\section{Acknowledgments}

Giulio Cuccodoro (MHNG), Martin Fikáček (NMPC), and Volker Brachat (Geretsried, Germany) kindly arranged loans of the material used in this study. Zi-Wei Yin thanks Giulio Cuccodoro, Ivan Löbl (MHNG), and Shûhei Nomura for their hospitality and various kinds of support during his visits to Geneva $(2015,2018)$ and Japan (2012). Two anonymous reviewers provided helpful comments which considerably improved the paper. Financial support was provided by the National Natural Science Foundation of China (No. 31872965), and Science and Technology Commission of Shanghai Municipality, China (19QA1406600) awarded to ZWY.

\section{References}

BEKCHIEV R. 2010: Description of the second species of the genus Taiwanophodes Hlaváč, 2002 (Coleoptera: Staphylinidae: Pselaphinae) from Vietnam. Russian Entomological Journal 19(3): 183-185.

BEKCHIEV R., HLAVÁČ P. \& NOMURA S. 2013: A taxonomic revision of Tyrini of the Oriental region. V. Revision of the genus Lasinus Sharp, 1874 (Coleoptera, Staphylinidae, Pselaphinae). ZooKeys 340: 21-42.

BEKCHIEV R., YIN Z.-W., VU M. Q., TRA M. H. \& NGUYEN H. H. 2019: Description of a new Pselaphodes Westwood (Coleoptera: Staphylinidae: Pselaphinae) from Vietnam. Biodiversity Data Journal 7(e46327): 1-6.

CHANDLER D. S. 2001: Biology, morphology, and systematics of the ant-like litter beetles of Australia (Coleoptera: Staphylinidae: Pselaphinae). Memoirs on Entomology International 15: 1-560.

HLAVÁČ P. 2003: A taxonomic revision of the Tyrini of the Oriental Region. II. Systematic study on the genus Pselaphodes and its allied genera (Coleoptera: Staphylinidae: Pselaphinae). Annales de la Société Entomologique de France (Nouvelle Série) 38(3): 283-297.

HLAVÁČ P. \& NOMURA S. 2001: A taxonomic revision of Tyrini of the Oriental Region. I. Paralasinus (Coleoptera, Staphylinidae, Pselaphinae), a new genus of Tyrina from Indochina. Elytra 29(1): $163-174$.

HUANG M.-C., LI L.-Z. \& YIN Z.-W. 2018a: Eleven new species and a new country record of Pselaphodes (Coleoptera: Staphylinidae: Pselaphinae) from China, with a revised checklist of world species. Acta Entomologica Musei Nationalis Pragae 58(2): 457-478.

HUANG M.-C., LI L.-Z. \& YIN Z.-W. 2018b: Four new species of Pselaphodes Westwood (Coleoptera: Staphylinidae: Pselaphinae) from Thailand, Laos, and China. Zootaxa 4472(1): 100-110.

HUANG M.-C. \& YIN Z.-W. 2018: Two new species of Nomuraius Hlaváč (Coleoptera: Staphylinidae: Pselaphinae) from southern China. Zootaxa 4399(4): 571-578.

HUANG M.-C. \& YIN Z.-W. 2019: The Pselaphodes (Coleoptera: Staphylinidae: Pselaphinae) of Nepal. Revue Suisse de Zoologie 126(2): 165-196. 
LI N. \& YIN Z.-W. 2020: The first Sri Lankan species of Labomimus Sharp (Coleoptera: Staphylinidae: Pselaphinae). Zootaxa 4809(2): 397-400.

NOMURA S. 2013: A checklist of the Pselaphine species (Coleoptera, Staphylinidae) of Vietnam. Japanese Journal of Systematic Entomology 19(2): 233-242.

NOMURA S. 2019: List of the Pselaphine Beetles (Insecta, Coleoptera, Staphylinidae) collected from central Laos in 2013-2014. Bulletin of the National Museum of Nature and Science, Series A 45(2): 61-72.

NOMURA S. \& PHAM H. T. 2019: List of pselaphine species (Insecta, Coleoptera, Staphylinidae) collected by light traps from North Vietnam in 2014 with supplements and corrections to the check-list of Nomura (2013). Bulletin of the National Museum of Nature and Science, Series A 45(2): 73-83.

YIN Z.-W. 2019: Two new species and new records of the Pselaphodescomplex of genera from China (Coleoptera: Staphylinidae: Pselaphinae). Revue Suisse de Zoologie 126(2): 197-202.

YIN Z.-W., BEKCHIEV R. \& LI L.-Z. 2014: A new species of Lasinus Sharp (Coleoptera: Staphylinidae: Pselaphinae) from East China Zootaxa 3764(5): 597-600.

YIN Z.-W., HLAVÁČ P. \& LI L.-Z. 2013b: Further studies on the Pselaphodes complex of genera from China (Coleoptera, Staphylinidae, Pselaphinae). ZooKeys 275: 23-65.

YIN Z.-W. \& LI L.-Z. 2013a: Five new species of the genera Labomimus and Linan from Guangxi, South China (Coleoptera: Staphylinidae:
Pselaphinae). Acta Entomologica Musei Nationalis Pragae 53(1): $141-153$.

YIN Z.-W. \& LI L.-Z. 2013b: Taxonomic notes on the genus Nomuraius Hlaváč (Staphylinidae: Pselaphinae). Revue Suisse de Zoologie 120(4): 563-573.

YIN Z.-W., LI L.-Z. \& ZHAO M.-J. 2012: Two new species of Pselaphodes Westwood and new record of Taiwanophodes minor Hlaváč from South China (Coleoptera, Staphylinidae, Pselaphinae). ZooKeys 175: $75-86$.

YIN Z.-W., NOMURA S. \& LI L.-Z. 2013a: New species and new records of the Pselaphodes complex of genera (Staphylinidae: Pselaphinae: Tyrini) from China. Annales Zoologici 63(2): 343-356.

YIN Z.-W. \& ZHANG Y.-Q. 2019: First species of Labomimus Sharp (Coleoptera: Staphylinidae: Pselaphinae) from Nepalese Himalaya. The Coleopterists Bulletin 73(3): 722-726.

ZHANG Y.-Q., LI L.-Z. \& YIN Z.-W. 2018: Six new species and a new record of Linan Hlaváč in China, with a key to species (Coleoptera, Staphylinidae, Pselaphinae). ZooKeys 793: 115-133.

ZHANG Y.-Q., LI L.-Z. \& YIN Z.-W. 2019: Fifteen new species and a new country record of Labomimus Sharp from China, with a checklist of world species (Coleoptera: Staphylinidae: Pselaphinae). Zootaxa 4554(2): 497-531.

ZHANG Y.-Q. \& YIN Z.-W. 2019: Three new species of Labomimus Sharp (Coleoptera: Staphylinidae: Pselaphinae) from Taiwan, China, with an updated key for L. shibatai Sawada-group. Zootaxa 4586(3): 553-561. 
